\title{
¿Impact of Evaporation and Precipitation on Estuarine Mixing
}

\author{
MARvin LorenZ, ${ }^{\mathrm{a}}$ KNUT KlingBeil, ${ }^{\mathrm{a}}$ AND Hans BurCharD ${ }^{\mathrm{a}}$ \\ ${ }^{\mathrm{a}}$ Leibniz Institute for Baltic Sea Research Warnemünde, Rostock, Germany
}

(Manuscript received 15 July 2020, in final form 28 January 2021)

\begin{abstract}
Recent studies could link the quantities of estuarine exchange flows to the volume-integrated mixing inside an estuary, where mixing is defined as the destruction of salinity variance. The existing mixing relations quantify mixing inside an estuary by the net boundary fluxes of volume, salinity, and salinity variance, which are quantified as Knudsen or total exchange flow bulk values. So far, river runoff is the only freshwater flux included, and the freshwater exchange due to precipitation and evaporation is neglected. Yet, the latter is the driving force of inverse estuaries, which could not be described by the existing relations. To close this gap, this study considers evaporation and precipitation to complete the existing mixing relations by including cross-surface salinity variance transport. This allows decomposing the mixing into a riverine and a surface transport contribution. The improved relations are tested against idealized two-dimensional numerical simulations of different combinations of freshwater forcing. The mixing diagnosed from the model results agrees exactly with the derived mixing relation. An annual hindcast simulation of the Persian Gulf is then used to test the mixing relations, both exact and approximated, e.g., long-term averaged, for a realistic inverse estuary. The results show that the annual mean mixing contributions of river discharge and evaporation are almost equal, although the freshwater transport due to evaporation is about one order of magnitude larger than the river runoff.
\end{abstract}

KEYWORDS: Estuaries; Seas/gulfs/bays; Mixing; Evaporation

\section{Introduction}

Classical estuaries are mixing hotspots where river water of zero salinity is mixed with inflowing seawater into the properties of outflowing estuarine water, flowing back into the ocean. Mixing is the key mechanism that transforms the properties of the inflowing water into the properties of outflowing water, e.g., salinity and temperature. Reliable and representative quantification of estuarine mixing is necessary to advance in understanding the interaction between dynamics and changes in salinity structure in estuaries. In this study, we quantify mixing as the destruction of salinity variance per unit volume $\chi^{s}$ (Nash and Moum 2002; Burchard and Rennau 2008; Burchard et al. 2009; Wang et al. 2017; Li et al. 2018; MacCready et al. 2018; Burchard et al. 2019; Warner et al. 2020), since it best characterizes the transformation of river water to ocean water as discussed by MacCready et al. (2018) and Burchard et al. (2019). By evaluating the salinity variance budget in terms of the Knudsen relations (Knudsen 1900), MacCready et al. (2018) relate the long-term average, estuarywide mixing $M$ to the characteristics of the exchange flow and river discharge,

$$
M \approx s_{\text {in }} s_{\text {out }} Q_{r},
$$

where $s_{\text {in }}$ and $s_{\text {out }}$ are the bulk values of the salinities of the inflow and outflow, and $Q_{r}$ is the river discharge. For the

\footnotetext{
D Denotes content that is immediately available upon publication as open access.

Corresponding author: Marvin Lorenz, marvin.lorenz@ io-warnemuende.de
}

computation of these bulk values, the total exchange flow (TEF) analysis framework (MacCready 2011) is used. Burchard et al. (2019) generalized the approximate long-term averaged mixing relation (1) to an exact transient relation. The mixing $M$ can be used to compare the mixing of estuaries with each other independent of the mechanisms responsible for the mixing, e.g., tidal with nontidal estuaries.

While the existing mixing relations, either stationary or transient, can be applied to classical estuaries with river runoff as the only freshwater forcing, they do not cover inverse estuaries since evaporation is neglected (MacCready et al. 2018; Burchard et al. 2019). Furthermore, tropical and subtropical estuaries can be a combination of inverse and classical estuaries (Valle-Levinson 2010). Strong evaporation may form socalled salt plugs, a region of maximum salinities greater than the ocean salinity inside the estuary (Wolanski 1986). For such estuaries, the freshwater forcing may change between seasons, i.e., the estuary may change from a classical estuary type during the wet season to an inverse type in dry season (Valle-Levinson and Bosley 2003).

Simply replacing the incoming river runoff $Q_{r}$ in (1) with the outgoing evaporation transport $Q_{\text {evap }}, Q_{\text {evap }}<0$, would result in $M<0$. For the exchange flow, this might make sense, as the inflowing water is transformed into more saline outflowing water which requires demixing of the inflowing water since no salt is added in the estuary. But $M$ is by definition a strictly positive number. As we will show in this study, this problem is solved by adding a cross-surface salinity square transport proportional to the square of the surface salinity, ensuring $M \geq$ 0 . Stern (1968) already states that salt variance added by surface fluxes has to be destructed on microscales due to molecular diffusion to achieve a steady-state solution for the World Ocean. 
By this generalization of the Knudsen (1900) relations and the MacCready et al. (2018) mixing relation, not only estuaries may be characterized, but also bays, lagoons, and shallow coastal zones which are influenced by precipitation or evaporation. Furthermore, these relations provide a very good estimate of mixing by evaluating boundary transports without the need for a three-dimensional numerical model.

The paper is structured as follows: first, we derive the exact mixing relation including the cross-surface freshwater transport in section 2, as an extension to the relations presented in MacCready et al. (2018) and Burchard et al. (2019). We further simplify the exact relation by different assumptions that make it easier to apply. In section 3 we present a schematic box model explaining the new, simplified mixing relation for a strictly inverse estuary. In section 4 we present the application of the new mixing relations to idealized, two-dimensional estuary simulations, and the first application to a realistic, three-dimensional simulation, the Persian Gulf. In section 5 we discuss the results of this study and conclude.

\section{Derivation of the mixing relations}

\section{a. Budget equations}

\section{1) VOLUME}

Following the derivation of Burchard et al. (2019) we consider Cartesian coordinates $(x, y, z)$, the time $t$ and the velocity vector $(u, v, w)$. We start at the Reynolds-averaged continuity equation in Boussinesq approximation,

$$
\partial_{x} u+\partial_{y} v+\partial_{z} w=0 .
$$

We consider the kinematic boundary conditions at the surface $\eta$ and the bottom $-H$,

$$
\begin{aligned}
& w=\partial_{t} \eta+u \partial_{x} \eta+v \partial_{y} \eta+E-P \text { for } z=\eta \\
& w=-u \partial_{x} H-v \partial_{y} H \text { for } z=-H
\end{aligned}
$$

where $E$ is the evaporation rate and $P$ the precipitation rate (both in $\mathrm{m} \mathrm{s}^{-1}$ ), and $H$ is the water depth. Carrying out the volume integration over the whole volume $V$ of the estuary and considering the kinematic boundary conditions, (3) and (4), the continuity equation (2) reads as

$$
\partial_{t} V=-\int_{A_{b}} u_{n} d A-\int_{A_{r}} u_{n} d A+\int_{A_{\text {surf }}}(P-E) d A,
$$

where $A_{b}$ describes the open boundary area, $A_{r}$ the river boundary area for which we assume that the river water is fresh and the salinity along $A_{r}$ is always zero, $A_{\text {surf }}$ the surface area, and $u_{n}$ denotes the normal velocity component (positive outwards).

\section{2) SALINITY}

The Reynolds-averaged salinity equation reads as

$$
\begin{gathered}
\partial_{t} s+\partial_{x}(u s)+\partial_{y}(v s)+\partial_{z}(w s)-\partial_{x}\left(K_{h} \partial_{x} s\right) \\
-\partial_{y}\left(K_{h} \partial_{y} s\right)-\partial_{z}\left(K_{v} \partial_{z} s\right)=0
\end{gathered}
$$

where we used the eddy-diffusivity assumption for turbulent salinity fluxes. The variables $K_{h}$ and $K_{v}$ denote the horizontal and vertical eddy diffusivities, respectively, and $s$ the salinity. Volume integration of the salinity equation (6) requires boundary conditions for the diffusive salt flux. We demand that there is no net salt flux through the surface and the bottom. The surface boundary condition for salt flux reads therefore as

$K_{h}\left(\partial_{x} s\right)\left(\partial_{x} \eta\right)+K_{h}\left(\partial_{y} s\right)\left(\partial_{y} \eta\right)-K_{v} \partial_{z} s=-(E-P) s$ for $z=\eta$,

(Beron-Vera et al. 1999; Warren 2009; Nurser and Griffies 2019) and at the bottom as

$$
-K_{h}\left(\partial_{x} s\right)\left(\partial_{x} H\right)-K_{h}\left(\partial_{y} s\right)\left(\partial_{y} H\right)-K_{v} \partial_{z} s=0 \quad \text { for } \quad z=-H .
$$

In (7) the diffusive salt flux at the surface is necessary to compensate the advective salt flux associated with (3). With these boundary conditions the volume-integrated salinity equation (6) reads as

$$
\partial_{t} \int_{V} s d V=-\int_{A_{b}}\left(s u_{n}-K_{h} \partial_{n} s\right) d A \equiv-\int_{A_{b}} f_{n}^{s} d A,
$$

with $\partial_{n}$ denoting the derivative normal to the transect. Furthermore, we define the tracer flux

$$
f_{n}^{c} \equiv c u_{n}-K_{h} \partial_{n} c
$$

with $c$ being a generic tracer, in Eq. (9) $c=s$. Equation (9) only allows exchanging salt through the open ocean boundary.

\section{3) SALINITY SQUARE}

Multiplication of (6) with $2 s$ leads to an equation for $s^{2}$,

$$
\begin{gathered}
\partial_{t} s^{2}+\partial_{x}\left(u s^{2}\right)+\partial_{y}\left(v s^{2}\right)+\partial_{z}\left(w s^{2}\right)-\partial_{x}\left(K_{h} \partial_{x} s^{2}\right) \\
-\partial_{y}\left(K_{h} \partial_{y} s^{2}\right)-\partial_{z}\left(K_{v} \partial_{z} s^{2}\right)=-\chi^{s}
\end{gathered}
$$

with the local salt mixing (Burchard and Rennau 2008)

$$
\chi^{s}=2\left[K_{h}\left(\partial_{x} s\right)^{2}+K_{h}\left(\partial_{y} s\right)^{2}+K_{v}\left(\partial_{z} s\right)^{2}\right] .
$$

By multiplication of (7) and (8) with $2 s$, one finds corresponding boundary conditions for $s^{2}$,

$$
\begin{aligned}
& K_{h}\left(\partial_{x} s^{2}\right)\left(\partial_{x} \eta\right)+K_{h}\left(\partial_{y} s^{2}\right)\left(\partial_{y} \eta\right)-K_{v} \partial_{z} s^{2}= \\
& -2(E-P) s^{2} \text { for } z=\eta,
\end{aligned}
$$

and

$-K_{h}\left(\partial_{x} s^{2}\right)\left(\partial_{x} H\right)-K_{h}\left(\partial_{y} s^{2}\right)\left(\partial_{y} H\right)-K_{v} \partial_{z} s^{2}=0 \quad$ for $\quad z=-H$.

Volume integration of (11) and using the derived boundary conditions (13) and (14) yield

$\partial_{t} \int_{V} s^{2} d V=-\int_{A_{b}} f_{n}^{s^{2}} d A+\int_{A_{\text {surf }}} s^{2}(E-P) d A-\int_{V} \chi^{s} d V$, 
where the second term on the right-hand side denotes the salinity squared transport due to the net surface freshwater transport.

\section{4) SALINITY VARIANCE}

Similarly, an equation for the local salinity variance $s^{\prime 2}$, with $s^{\prime}=s-\bar{s}$, where $\bar{s}$ denotes the volume-averaged salinity, $\bar{s}=(1 / V) \int s d V$, can be derived. By subtracting $\partial_{t} \bar{s}$ from the salinity equation (6) and multiplying with $2 s^{\prime}$ one finds

$$
\begin{gathered}
\partial_{t} s^{\prime 2}+\partial_{x}\left(u s^{\prime 2}\right)+\partial_{y}\left(v s^{\prime 2}\right)+\partial_{z}\left(w s^{\prime 2}\right)-\partial_{x}\left(K_{h} \partial_{x} s^{\prime 2}\right) \\
-\partial_{y}\left(K_{h} \partial_{y} s^{\prime 2}\right)-\partial_{z}\left(K_{v} \partial_{z} s^{\prime 2}\right)=-\chi^{s}-2 s^{\prime} \partial_{t} \bar{s} .
\end{gathered}
$$

The local salt mixing $\chi^{s}$ describes the destruction of salinity variance (and salinity square) per unit volume by turbulent eddies. For steady-state, homogeneous turbulence, $\chi^{s}$ is equal to the destruction of salinity variance on molecular scale (Nash and Moum 2002). The respective variance boundary conditions at the surface and the bottom can be derived by multiplying (7) and (8) with $2 s^{\prime}$ :

$$
\begin{aligned}
& K_{h}\left(\partial_{x} s^{\prime 2}\right)\left(\partial_{x} \eta\right)+K_{h}\left(\partial_{y} s^{\prime 2}\right)\left(\partial_{y} \eta\right)-K_{v} \partial_{z} s^{\prime 2} \\
& \quad=-2(E-P) s^{2}+2(E-P) s \bar{s} \text { for } z=\eta,
\end{aligned}
$$

and

$$
-K_{h}\left(\partial_{x} s^{\prime 2}\right)\left(\partial_{x} H\right)-K_{h}\left(\partial_{y} s^{\prime 2}\right)\left(\partial_{y} H\right)-K_{v} \partial_{z} s^{\prime 2}=0 \text { for } z=-H .
$$

By integrating over the estuarine volume and considering the boundary conditions (17) and (18), (16) yields

$$
\begin{aligned}
\partial_{t} \int_{V} s^{\prime 2} d V= & -\int_{A_{b}} f_{n}^{s^{\prime 2}} d A-\bar{s}^{2} \int_{A_{r}} u_{n} d A \\
& +\int_{A_{\text {surf }}}\left(s^{2}-\bar{s}^{2}\right)(E-P) d A-\int_{V} \chi^{s} d V,
\end{aligned}
$$

where the first term on the right-hand side denotes the variance exchange with the ocean, the second term accounts the change of the mean salinity due to river runoff, and the third term accounts variance changes due to evaporation and precipitation. The integrated salt mixing $\chi^{s}$ denotes a sink in both the salinity squared equation (15) and the salinity variance equation (19). The formalism of the salinity squared equation (15) has the advantage that it only depends on boundary fluxes and not on any internal information of the estuary. The variance on the other hand depends on the mean salinity $\bar{s}$ which is a volumeintegrated property. Therefore, the salinity squared formalism is easier to use and apply (Burchard et al. 2019).

\section{b. Time averaging and reformulation in terms of TEF bulk values}

Using the total exchange flow (TEF) analysis framework (MacCready 2011; Burchard et al. 2018; Lorenz et al. 2019), which allows a proper computation of bulk values characterizing the net exchange flow of an estuary with the ocean, we want to express the volume, salinity, salinity squared, and salinity variance budget in terms of bulk values. In the TEF analysis framework the transport of any tracer $c$ above a certain salinity $S$ through any cross section is defined as

$$
Q^{c}(S)=-\left\langle\int_{A(S)} f_{n}^{c} d A\right\rangle,
$$

with $A(S)$ being the fraction of the transect with $s>S$ (MacCready 2011) and \langle\rangle denotes temporal averaging. The inflowing and outflowing bulk properties are defined as the fraction of inflowing/outflowing tracer transport divided by the respective volume transport:

$$
c_{\text {in }}=\frac{Q_{\text {in }}^{c}}{Q_{\text {in }}}, \quad c_{\text {out }}=\frac{Q_{\text {out }}^{c}}{Q_{\text {out }}},
$$

where $Q_{\text {in }}^{c} \geq 0$ and $Q_{\text {out }}^{c} \leq 0$ can be computed from $Q^{c}(S)$ with considerations of the extreme values (see Lorenz et al. 2019). With $c=1$, the volume transport bulk values, $Q_{\text {in }}, Q_{\text {out }}$, their respective bulk salinities $(c=s), s_{\text {in }}, s_{\text {out }}$, bulk salinities squared $\left(c=s^{2}\right),\left(s^{2}\right)_{\text {in }},\left(s^{2}\right)_{\text {out }}$, bulk salinity variances $\left(c=s^{2}\right),\left(s^{\prime 2}\right)_{\text {in }}$, $\left(s^{2}\right)_{\text {out }}$, and with the definitions of river discharge

$$
Q_{r}=-\left\langle\int_{A_{r}} u_{n} d A\right\rangle
$$

surface freshwater transport

$$
Q_{\text {surf }}=-\left\langle\int_{A_{\text {surf }}}(E-P) d A\right\rangle=Q_{\text {evap }}+Q_{\text {precip }},
$$

with $Q_{\text {evap }} \leq 0, Q_{\text {precip }} \geq 0$, surface transport of salinity squared

$$
F_{\text {surf }}^{s^{2}}=\left\langle\int_{A_{\text {surf }}} s^{2}(E-P) d A\right\rangle,
$$

and volume integrated salt mixing

$$
M=\left\langle\int_{V} \chi^{s} d V\right\rangle
$$

where $M \geq 0$, one can rewrite the time-averaged budget equations (5), (9), (15), and (19):

$$
\begin{aligned}
\delta V & =\left\langle\partial_{t} V\right\rangle=Q(0)+Q_{r}+Q_{\text {surf }}=Q_{\text {in }}+Q_{\text {out }}+Q_{r}+Q_{\text {surf }} \\
\delta S & =\left\langle\partial_{t} \int_{V} s d V\right\rangle=Q^{s}(0)=Q_{\text {in }}^{s}+Q_{\text {out }}^{s}=Q_{\text {in }} s_{\text {in }}+Q_{\text {out }} s_{\text {out }} \\
\delta S^{2} & =\left\langle\partial_{t} \int_{V} s^{2} d V\right\rangle=Q^{s^{2}}(0)+F_{\text {surf }}^{s^{2}}-M \\
& =Q_{\text {in }}\left(s^{2}\right)_{\text {in }}+Q_{\text {out }}\left(s^{2}\right)_{\text {out }}+F_{\text {surf }}^{s^{2}}-M
\end{aligned}
$$

and 


$$
\begin{aligned}
\delta S^{\prime 2} & =\left\langle\partial_{t} \int_{V} s^{\prime 2} d V\right\rangle=Q^{s^{2}}(0)+F_{\text {surf }}^{s^{2}}-\left\langle\bar{s}^{2} \int_{A_{r}} u_{n} d A\right\rangle-\left\langle\int_{A_{\text {surf }}} \bar{s}^{2}(E-P) d A\right\rangle-M \\
& =Q_{\text {in }}\left(s^{\prime}\right)_{\text {in }}^{2}+Q_{\text {out }}\left(s^{\prime}\right)_{\text {out }}^{2}+F_{\text {surf }}^{s^{2}}-\left\langle\bar{s}^{2} \int_{A_{r}} u_{n} d A\right\rangle-\left\langle\int_{A_{\text {surf }}} \bar{s}^{2}(E-P) d A\right\rangle-M .
\end{aligned}
$$

Combining (26) and (27) leads to the time-dependent Knudsen relations (Knudsen 1900) including surface freshwater transport:

$$
\begin{gathered}
Q_{\text {in }}=\frac{s_{\text {out }}}{s_{\text {in }}-s_{\text {out }}}\left(Q_{r}-\delta V+Q_{\text {surf }}\right)+\frac{1}{s_{\text {in }}-s_{\text {out }}} \delta S, \\
Q_{\text {out }}=-\left[\frac{s_{\text {in }}}{s_{\text {in }}-s_{\text {out }}}\left(Q_{r}-\delta V+Q_{\text {surf }}\right)+\frac{1}{s_{\text {in }}-s_{\text {out }}} \delta S\right] .
\end{gathered}
$$

\section{c. Exact and approximated mixing relations}

Further combining (28) with (30) and (31) one finds a transient equation for the time-averaged, volume-integrated mixing:

$$
\begin{aligned}
M_{e}= & \frac{s_{\text {out }}\left(s^{2}\right)_{\text {in }}-s_{\text {in }}\left(s^{2}\right)_{\text {out }}}{s_{\text {in }}-s_{\text {out }}}\left(Q_{r}-\delta V+Q_{\text {surf }}\right) \\
& +\frac{\left(s^{2}\right)_{\text {in }}-\left(s^{2}\right)_{\text {out }}}{s_{\text {in }}-s_{\text {out }}} \delta S-\delta S^{2}+F_{\text {surf }}^{s^{2}},
\end{aligned}
$$

which is the same result as in Burchard et al. (2019) but with the additional freshwater input $Q_{\text {surf }}$ and an additional $s^{2}$ transport through the surface, $F_{\text {surf }}^{s^{2}}$. For $P=E=0$ (32) reduces to Eq. (36) of Burchard et al. (2019). Assuming constancy (subscript $c$ ), i.e., the temporal average of the squared property is the same as the time averaged quantity squared, e.g., $\left(s^{2}\right)_{\text {in }}=$ $\left(s_{\text {in }}\right)^{2},\left(s^{2}\right)_{\text {out }}=\left(s_{\text {out }}\right)^{2},(32)$ reduces to

$$
M_{c}=s_{\text {in }} s_{\text {sout }}\left(Q_{r}-\delta V+Q_{\text {surf }}\right)+\left(s_{\text {in }}+s_{\text {out }}\right) \delta S-\delta S^{2}+F_{\text {surf }}^{s^{2}} .
$$

If we assume periodicity or apply long-term averaging (subscript $p$ ), i.e., a tidally periodic estuary, or a long-term average of the estuary, the storage terms are approximately zero. The averaging period that is needed to justify this assumption, may strongly differ for each estuary, depending on its size and driving forces. Under these assumptions (32) yields

$$
M_{p}=\frac{s_{\text {out }}\left(s^{2}\right)_{\text {in }}-s_{\text {in }}\left(s^{2}\right)_{\text {out }}}{s_{\text {in }}-s_{\text {out }}}\left(Q_{r}+Q_{\text {surf }}\right)+F_{\text {surf }}^{s^{2}} .
$$

Considering both assumptions at the same time (subscript $c p$ ), (32) reads as

$$
M_{c p}=s_{\text {in }} s_{\text {out }}\left(Q_{r}+Q_{\text {surf }}\right)+F_{\text {surf }}^{s^{2}}
$$

which we can rewrite by defining a bulk surface salinity,

$$
s_{\text {surf }} \equiv\left[\left(s^{2}\right)_{\text {surf }}\right]^{1 / 2}=\left(-\frac{F_{\text {surf }}^{s^{2}}}{Q_{\text {surf }}}\right)^{1 / 2}
$$

to

$$
M_{c p}=s_{\text {in }} s_{\text {out }} Q_{r}+\left[s_{\text {in }} s_{\text {out }}-\left(s_{\text {surf }}\right)^{2}\right] Q_{\text {surf }} .
$$

The relation consists of two terms, each related to different forcing: the mixing term due to river discharge and a mixing term due to precipitation and evaporation. For vanishing surface freshwater fluxes (37) reduces to (1), established by MacCready et al. (2018).

Now we can also solve the problem stated in the introduction. For the case of evaporation only, (37) becomes

$$
M_{c p}=\left[s_{\text {in }} s_{\text {out }}-\left(s_{\text {surf }}\right)^{2}\right] Q_{\text {evap }} \text { for } \quad Q_{r}=Q_{\text {precip }}=0,
$$

and shows that despite $Q_{\text {evap }}<0$ a nonnegative $M_{c p}$ is obtained due the additional squared surface salinity term with $s_{\text {surf }} \geq$ $\left(s_{\text {in }} s_{\text {out }}\right)^{1 / 2}$. If the surface salinity of an inverse estuary does not fulfill this condition, the assumptions of stationarity and constancy are invalid.

For the case of precipitation only, (37) becomes

$$
M_{c p}=\left[s_{\text {in }} s_{\text {out }}-\left(s_{\text {surf }}\right)^{2}\right] Q_{\text {precip }} \text { for } Q_{r}=Q_{\text {evap }}=0,
$$

which requires $s_{\text {surf }} \leq\left(s_{\mathrm{in}} s_{\text {out }}\right)^{1 / 2}$. This condition is fulfilled, as for this kind of estuary the water column would be stratified and therefore $s_{\text {surf }} \leq s_{\text {out }} \leq s_{\text {in }}$.

\section{Simplistic box model}

To exemplify the derived mixing relation (35) for an inverse estuary, we assume a box model as shown in Fig. 1 with $Q_{r}=$ $\delta V=\delta S=0$. The steady-state estuary consisting of a surface layer (volume $V_{\text {surf }}$ with salinity $s_{\text {surf }}$ ) and a bottom layer (volume $V_{b}$ with salinity $s_{\text {out }}$ ) (see Fig. 1a) is maintained by the coaction of evaporation and inverse estuarine circulation during an infinitesimal time interval $\Delta t$. We describe the process of evaporation via $Q_{\text {surf }}<0$ as spatially constant removal of freshwater from the saline surface volume. This freshwater loss increases the surface salinity from $s_{\text {surf }}$ to $s_{\text {surf }}^{*}$ (see Fig. 1b). The volume in the estuary is replenished by an exchange flow with inflowing ocean water $\left(Q_{\text {in }}, s_{\text {in }}\right)$ and an outflow of estuarine bottom water $\left(Q_{\text {out }}, s_{\text {out }}\right)$ keeping the salt in the estuary constant (Fig. 1c).

In the following the mixing necessary to maintain the steadystate shown in Fig. 1a, more precisely to return to it from the state shown in Fig. 1c, is calculated. The volume-integrated salinity squares for the different states are given by

$$
\begin{aligned}
& \Sigma_{a}=V_{\text {surf }}\left(s_{\text {surf }}\right)^{2}+V_{b}\left(s_{\text {out }}\right)^{2}, \\
& \Sigma_{b}=\left(V_{\text {surf }}+\Delta t Q_{\text {surf }}\right)\left(s_{\text {surf }}^{*}\right)^{2}+V_{b}\left(s_{\text {out }}\right)^{2},
\end{aligned}
$$


a)

b)

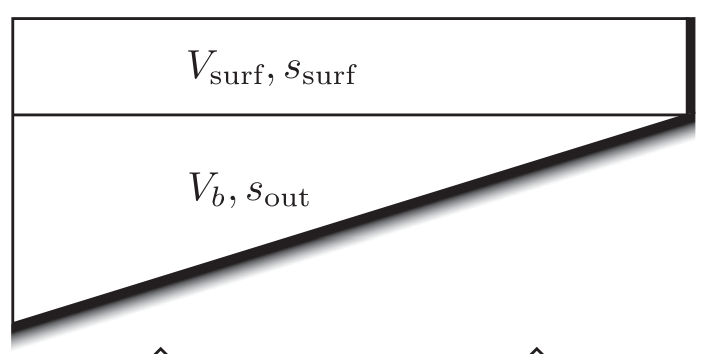

c)

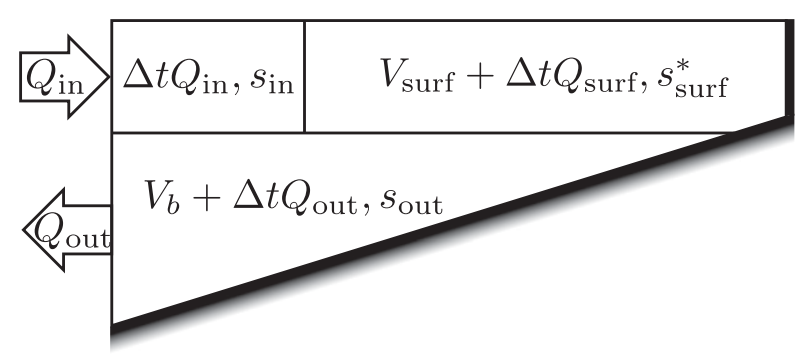

FIG. 1. Descriptive box model of a steady-state, instantaneous process of an inverse estuarine circulation due to evaporation. (a) The two-layered box with two well-mixed layers, a surface and bottom layer with different salinities. (b) The freshwater volume, $\Delta t Q_{\text {surf }}, Q_{\text {surf }}<0$, is removed from $V_{\text {surf }}$, which reduces the volume of the surface layer to $V_{\text {surf }}+\Delta t Q_{\text {surf }}$. The salt left behind by the evaporation process is mixed into the reduced surface volume, increasing the salinity $s_{\text {surf }}$ to $s_{\text {surf }}^{*}$. (c) The exchange flow is added. Its net volume flux replaces the evaporated freshwater. The inflow $Q_{\text {in }}$ of salinity $s_{\text {in }}$ enters the estuary, and $V_{b}$ is reduced by the outflow $Q_{\text {out }}$ to $V_{b}+\Delta t Q_{\text {out }}$. The salt content is not changed by the exchange flow. The state (a) is the long-term average result of states (b) and (c).

$$
\begin{aligned}
\Sigma_{c}= & \left(V_{\text {surf }}+\Delta t Q_{\text {surf }}\right)\left(s_{\text {surf }}^{*}\right)^{2}+\Delta t Q_{\text {in }}\left(s_{\text {in }}\right)^{2} \\
& +\left(V_{b}+\Delta t Q_{\text {out }}\right)\left(s_{\text {out }}\right)^{2} .
\end{aligned}
$$

The production of volume-integrated salinity square due to evaporation $\left(Q_{\text {surf }}<0\right)$ can be calculated as

$$
\frac{\Sigma_{b}-\Sigma_{a}}{\Delta t}=-\frac{1}{1+\frac{\Delta t Q_{\text {surf }}}{V_{\text {surf }}}}\left(s_{\text {surf }}\right)^{2} Q_{\text {surf }}
$$

where salt conservation between states $a$ and $b$,

$$
V_{\text {surf }} S_{\text {surf }}=\left(V_{\text {surf }}+\Delta t Q_{\text {surf }}\right) s_{\text {surf }}^{*},
$$

has been used. With the help of the Knudsen relations (30) and (31), the change of volume-integrated salinity square due to the exchange flow can be quantified as

$$
\frac{\Sigma_{c}-\Sigma_{b}}{\Delta t}=s_{\text {in }} s_{\text {out }} Q_{\text {surf }} .
$$

The mixing required to mix state $c$ back to state $a$ is given by $\left(\Sigma_{c}-\Sigma_{a}\right) / \Delta t$ and thus

$$
M_{c p}=\lim _{\Delta t \rightarrow 0} \frac{\left(\Sigma_{c}-\Sigma_{b}\right)+\left(\Sigma_{b}-\Sigma_{a}\right)}{\Delta t}=\left[s_{\text {in }} s_{\text {out }}-\left(s_{\text {surf }}\right)^{2}\right] Q_{\text {surf }},
$$

which is the same result as in (38). The variance change $\left(\Sigma_{b}-\right.$ $\left.\Sigma_{a}\right) / \Delta t$ in (43) is equivalent to the additional $s^{2}$ transport $F_{\text {surf }}^{s^{2}}$. For this simple, steady-state (periodic) box model with an inflow and outflow of constant salinity, the two components balancing the mixing $M_{c p}$ are well illustrated: the salinity square (variance) loss due to the exchange flow and the salinity square (variance) gain due to evaporation.

\section{Numerical model setups}

To test the derived relations (32)-(35) in a numerical model, we employ a 2D model similar to the setup of Warner et al. (2005) and Burchard et al. (2019), and a realistic threedimensional model of the Persian Gulf, also known as Arabian Gulf. The model of our choice is the General Estuarine Transport Model (GETM; Burchard and Bolding 2002), a coastal ocean model, solving the hydrostatic Boussinesq equations (Klingbeil et al. 2018). For turbulence closure, the turbulence module of the General Ocean Turbulence Model (GOTM; Burchard and Bolding 2001) is coupled to the model. Here, we use the $\kappa-\epsilon$ model in all simulations as well as the total variation diminishing (TVD) Superbee scheme (Pietrzak 1998) for the advection discretization. Further details on the different setups are described in the respective sections.

\section{a. Calculation of mixing and $F_{\text {surf }}^{s^{2}}$ in the model}

In GETM all forms of variance changes are quantified in every grid cell according to the discrete variance decay analysis method of Klingbeil et al. (2014). This also includes the application of (43) to the single surface grid cells. The corresponding variance change defines the local contribution to $F_{\text {surf }}^{s^{2}}$. The total mixing of the model $M_{\text {model }}^{\text {tot }}$ consists of physical $M_{\text {model }}^{\text {phy }}$ and numerical $M_{\text {model }}^{\text {num }}$ contributions, originating from the turbulence parameterization and the spurious mixing ubiquitous to advection schemes, respectively. All time-averaged quantities are calculated during runtime as thickness-weighted averages (Klingbeil et al. 2019).

\section{b. Idealized two-dimensional simulations}

First, we applied the relations (32)-(35) to an idealized setup with different forcing. Furthermore, we investigated approximations of the surface salinity square transport, since the exact 


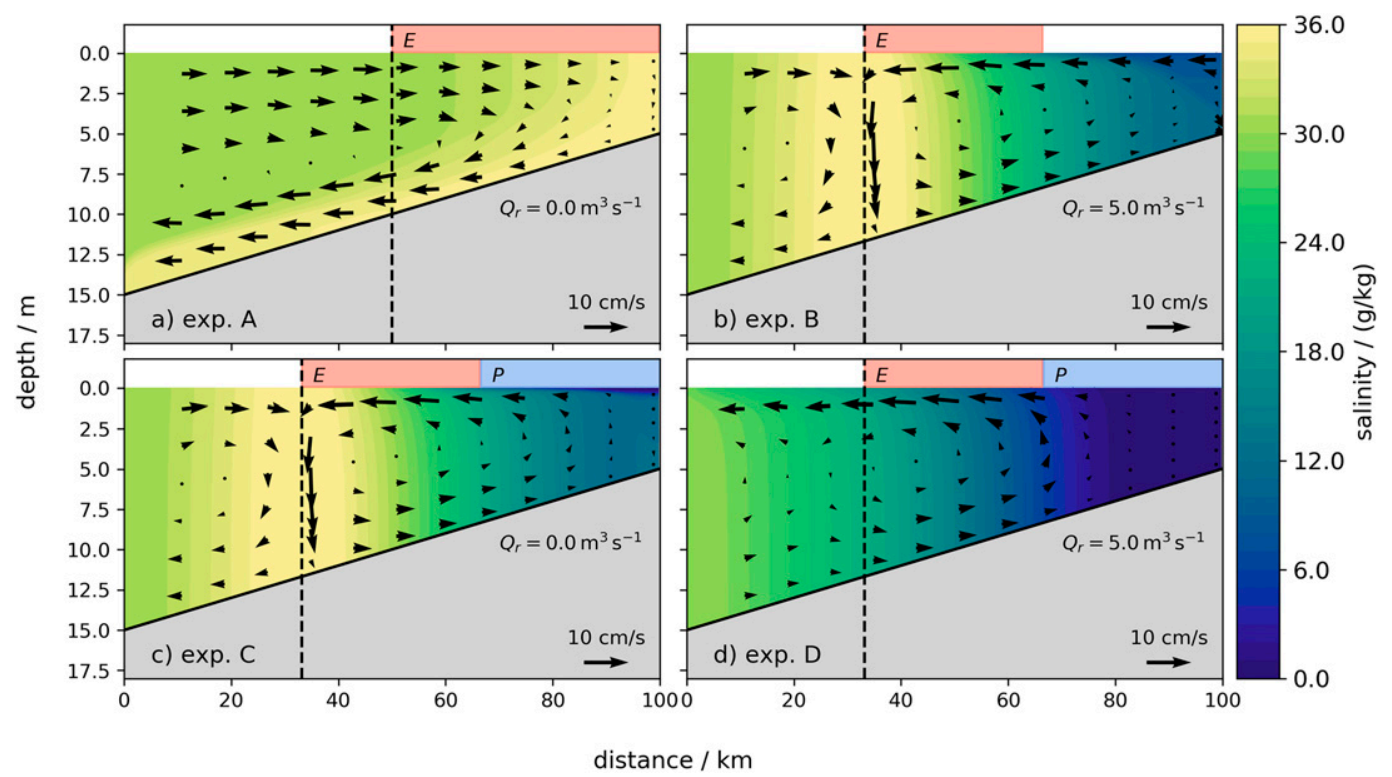

FIG. 2. Idealized simulations: long-term average states of salinity distribution and residual circulation ( $w$ scaled with the local aspect ratio) averaged over 100 tidal cycles for different freshwater forcing: (a) evaporation prescribed over half the domain, (b) evaporation prescribed over one-third in the middle of the domain with river discharge, (c) evaporation over one-third in the middle of the domain with precipitation over the right third of the domain, (d) evaporation over one-third in the middle of the domain with precipitation over the right third of the domain plus additional river discharge; see Table 1 for more details. The dashed lines mark the transects that are evaluated to compute the mixing inside the estuary, i.e., right of the transect. The results of this evaluation are listed in Table 2 .

value is difficult to observe in high temporal and spatial resolution. The idealized estuary is $100 \mathrm{~km}$ long with a resolution of $d x=d y=200 \mathrm{~m}$. The topography is linearly increasing from 15-m depth at the ocean boundary to 5-m depth where the river is entering the domain, see Fig. 2. In the vertical 60 equally distributed $\sigma$-coordinates are used. The open boundary is prescribed with a constant salinity of $30 \mathrm{~g} \mathrm{~kg}^{-1}$, and an $\mathrm{M}_{2}$ tidal amplitude of $0.5 \mathrm{~m}$, if tides are applied. Freshwater transports that are river discharge as well as spatially integrated precipitation or evaporation, are all $5.0 \mathrm{~m}^{3} \mathrm{~s}^{-1}$. The TEF analysis is done during the model run for each baroclinic time step using 250 equidistant salinity bins from 0 to $40.0 \mathrm{~g} \mathrm{~kg}^{-1}$ as proposed by Lorenz et al. (2019). Depending on the experiment, see Table 1, different combinations of forcing are applied. The temperature is kept constant in these simulations. The different experiment simulations are integrated into a quasi-periodic state (500 tidal cycles), which is not a real periodic state due to waves forced by the surface flux gradients which propagate through the domain, flushing the high salinity water from the shallow part out of the estuary. Therefore, a long-term average of 100 tidal cycles is carried out to minimize the storage terms in the budget equations, see Fig. 2.

Experiment A (Table 1, Fig. 2a) demonstrates the bottom water formation solely due to evaporation, without any tides. Over the inner half of the domain, constant evaporation is prescribed. Due to the slope of the bathymetry, the salinity increases toward the shallow end and creates a baroclinic pressure gradient. Opposing a barotropic pressure gradient due to the lower surface at the coast is formed. The water of high salinities flows down the slope at the bottom, whereas the water of less salinity enters the evaporation zone, indicated by the arrows in Fig. 2a. As shown in Table 2, $M_{\text {model }}^{\text {tot }}=M_{e}$ holds exactly down to machine accuracy. Evaluating the approximations, $M_{p}$ shows a small discrepancy to $M_{e}$, whereas $M_{c}$ shows a large deviation, although $\left(s^{2}\right)_{\text {in }} \approx\left(s_{\text {in }}\right)^{2}$ and $\left(s^{2}\right)_{\text {out }} \approx$ $\left(s_{\text {out }}\right)^{2}$. Therefore, $M_{c p}$ also shows a large deviation. This is due to the overall low mixing in this simulation.

Experiment B adds river discharge, $Q_{r}=5 \mathrm{~m}^{3} \mathrm{~s}^{-1}$, to experiment $\mathrm{A}$, while also shifting the evaporation area further offshore and reducing the area from half the domain to onethird of the domain, keeping the freshwater loss to $-5 \mathrm{~m}^{3} \mathrm{~s}^{-1}$. Furthermore, a semidiurnal $\mathrm{M}_{2}$ tide of $0.5 \mathrm{~m}$ is prescribed. The resulting salinity distribution, see Fig. 2b, shows a salinity maximum near the left border of the evaporation zone of $\sim 37 \mathrm{~g} \mathrm{~kg}^{-1}$, a so-called salt plug which can be often found in

TABLE 1. Overview of four idealized model experiments of different combinations of freshwater forcing; $Q_{\text {evap }}$ and $Q_{\text {precip }}$ are the area integrated evaporation and precipitation rates of $E$ and $P$.

\begin{tabular}{ccccc}
\hline \hline Experiment & $\begin{array}{c}Q_{r} \\
\left(\mathrm{~m}^{3} \mathrm{~s}^{-1}\right)\end{array}$ & $\begin{array}{c}Q_{\text {evap }} \\
\left(\mathrm{m}^{3} \mathrm{~s}^{-1}\right)\end{array}$ & $\begin{array}{c}Q_{\text {precip }} \\
\left(\mathrm{m}^{3} \mathrm{~s}^{-1}\right)\end{array}$ & $\begin{array}{c}\mathrm{M}_{2} \\
\text { amplitude }(\mathrm{m})\end{array}$ \\
\hline A & 0.0 & -5.0 & 0.0 & 0.0 \\
B & 5.0 & -5.0 & 0.0 & 0.5 \\
C & 0.0 & -5.0 & 5.0 & 0.5 \\
D & 5.0 & -5.0 & 5.0 & 0.5 \\
\hline
\end{tabular}


TABLE 2. Results of the mixing analysis for the idealized model experiments listing the variables needed to compute the mixing with relations (32)-(35). In the model mixing is directly diagnosed $\left(M_{\text {model }}^{\text {tot }}\right)$ and split into physical and numerical contributions ( $\left.M_{\text {model }}^{\text {phy }}, M_{\text {model }}^{\text {num }}\right)$ to compare to the relations (Klingbeil et al. 2014). Although we only show rounded values, $M_{\text {model }}^{\text {tot }}$ and $M_{e}$ equal to machine accuracy.

\begin{tabular}{lcccc}
\hline \hline & Expt A & Expt B & Expt C & Expt D \\
\hline$s_{\text {in }} / \mathrm{g} \mathrm{kg}^{-1}$ & 30.00 & 36.63 & 36.57 & 24.04 \\
$s_{\text {out }} / \mathrm{g} \mathrm{kg}^{-1}$ & 32.67 & 37.34 & 37.12 & 13.98 \\
{$\left[\left(s^{2}\right)_{\mathrm{in}}\right]^{1 / 2} / \mathrm{g} \mathrm{kg}^{-1}$} & 30.00 & 36.63 & 36.58 & 24.05 \\
{$\left[\left(s^{2}\right)_{\text {out }}\right]^{1 / 2} / \mathrm{g} \mathrm{kg}^{-1}$} & 32.73 & 37.38 & 37.18 & 15.24 \\
$\delta V / \mathrm{m}^{3} \mathrm{~s}^{-1}$ & 0.00 & 0.36 & 0.34 & 0.30 \\
$\delta S / \mathrm{g} \mathrm{kg}^{-1} \mathrm{~m}^{3} \mathrm{~s}^{-1}$ & 1.18 & 5.55 & 6.94 & 8.48 \\
$\delta S^{2} /\left(\mathrm{g} \mathrm{kg}^{-1}\right)^{2} \mathrm{~m}^{3} \mathrm{~s}^{-1}$ & 65.3 & 237 & 339.3 & -35.16 \\
$F_{\text {surf }}^{s^{2}} /\left(\mathrm{g} \mathrm{kg}^{-1}\right)^{2} \mathrm{~m}^{3} \mathrm{~s}^{-1}$ & 5279 & 3982 & 3786 & 946.8 \\
$M_{e} /\left(\mathrm{g} \mathrm{kg}^{-1}\right)^{2} \mathrm{~m}^{3} \mathrm{~s}^{-1}$ & 212.3 & 3646 & 3464 & 2445 \\
$M_{c} /\left(\mathrm{g} \mathrm{kg}^{-1}\right)^{2} \mathrm{~m}^{3} \mathrm{~s}^{-1}$ & 403.9 & 3678 & 3495 & 2884 \\
$M_{p} /\left(\mathrm{g} \mathrm{kg}^{-1}\right)^{2} \mathrm{~m}^{3} \mathrm{~s}^{-1}$ & 203.6 & 3982 & 3786 & 2193 \\
$M_{c p} /\left(\mathrm{g} \mathrm{kg}^{-1}\right)^{2} \mathrm{~m}^{3} \mathrm{~s}^{-1}$ & 396.7 & 3982 & 3786 & 2628 \\
$M_{\text {model }}^{\text {tot }} /\left(\mathrm{g} \mathrm{kg}^{-1}\right)^{2} \mathrm{~m}^{3} \mathrm{~s}^{-1}$ & 212.3 & 3646 & 3464 & 2445 \\
$M_{\text {model }}^{\text {phy }} /\left(\mathrm{g} \mathrm{kg}^{-1}\right)^{2} \mathrm{~m}^{3} \mathrm{~s}^{-1}$ & 103.5 & 3438 & 2911 & 2413 \\
$M_{\text {model }}^{\text {num }} /\left(\mathrm{g} \mathrm{kg}^{-1}\right)^{2} \mathrm{~m}^{3} \mathrm{~s}^{-1}$ & 108.8 & 208 & 553 & 32 \\
\hline
\end{tabular}

tropical estuaries during dry season (Wolanski 1986; ValleLevinson and Bosley 2003). In the salt plug, the mean velocity is downward. The circulation along the analyzed transect follows an inverse circulation. In addition, due to the river discharge, a classical estuarine circulation is created near the coast, extending into the evaporation zone. There the strong evaporation is able to transform the brackish water to higher salinities than the prescribed $30 \mathrm{~g} \mathrm{~kg}^{-1}$ at the open boundary. Compared to the first experiment the mixing is larger by a factor of $\sim 20$, although $F_{\text {surf }}^{s^{2}}$ being smaller than in experiment A. This is due to the net freshwater transport which is $\approx 0$ across the transect in this case. For this experiment in contrast to experiment $\mathrm{A}$, the constancy approximation is better than the periodicity approximation.

Experiment $\mathrm{C}$ replaces the river discharge with a precipitation region in the coastal area, see Fig. 2c. The results show a similar salinity distribution to experiment $\mathrm{B}$ and the mixing is comparable as well. The major difference to experiment $\mathrm{B}$ is the numerical mixing that has more than doubled which can be explained by stronger salinity gradients since a thin surface layer of fresher water is maintained, see Fig. 2c. This strong salinity gradient is prone to be mixed due to numerical mixing.

Experiment D adds river discharge, yielding a net positive freshwater budget adding $5 \mathrm{~m}^{3} \mathrm{~s}^{-1}$ to the setup. The overall circulation follows a classical estuarine circulation with brackish water leaving the estuary at the surface, while saline water enters at the bottom, see Fig. 2d. The evaporation is not enough to form a salt plug as shown in experiments B and C. The surface salinity square transport $F_{\text {surf }}^{s^{2}}$ has the smallest value of all experiments due to the smallest surface salinities but adding $\sim 1 / 3$ of the total mixing. The rest of the mixing is due to the classic estuarine mixing as already described by MacCready et al. (2018) and Burchard et al. (2019). For this experiment, the constancy approximation leads to an overestimation, whereas the periodicity approximation leads to an underestimation.

We did some approximations of the exact surface salinity square transport in Table 3, which involve the easier to observe quantities: average sea surface salinity and integrated surface freshwater transport for all four experiments. Furthermore, we compare the definition of $s_{\text {surf }}$, Eq. (36), to model mean surface salinities. The best approximation for these experiments of the exact $F_{\text {surf }}^{s^{2}}$, where precipitation and evaporation occur in different regions, is achieved, when separately evaluating the salinity square transports due to evaporation and precipitation, i.e.,

$$
F_{\text {surf }}^{s^{2}} \approx-\left\langle\left(s_{\text {surf,model,evap }}\right)^{2}\right\rangle Q_{\text {evap }}+\left\langle\left(s_{\text {surf,model,precip }}\right)^{2}\right\rangle Q_{\text {precip }} .
$$

\section{c. Realistic three-dimensional simulation}

In this section we apply the mixing relations to a realistic model setup of a large, inverse estuary, the Persian Gulf, see Fig. 3.

We repeated the model simulation of Lorenz et al. (2020) for the year 2011 which is a representative year of the exchange flow of the Persian Gulf. The difference between this simulation and the results of Lorenz et al. (2020) is an online TEF

TABLE 3. Comparison of sea surface salinity and $F_{\text {surf }}^{s^{2}}$ to approximations using tidal averaged model results inside the estuary, i.e., right of the transects shown in Fig. 2. $\left\langle s_{\text {surf,model,evap }}\right\rangle$ and $\left\langle s_{\text {surf,model,precip }}\right\rangle$ are the respective mean surface salinities of the evaporation/ precipitation zones, whereas $\left\langle s_{\text {surf,model }}\right\rangle$ is the mean surface salinity of the whole estuary.

\begin{tabular}{|c|c|c|c|c|}
\hline & Expt A & Expt B & Expt $\mathrm{C}$ & Expt D \\
\hline$F_{\text {surf }}^{s^{2}} /\left(\mathrm{g} \mathrm{kg}^{-1}\right)^{2} \mathrm{~m}^{3} \mathrm{~s}^{-1}$ & 5279 & 3982 & 3786 & 946.8 \\
\hline$s_{\text {surf }}$ with Eq. $(36) / \mathrm{g} \mathrm{kg}^{-1}$ & 32.56 & 28.22 & $\infty$ & $\infty$ \\
\hline$\left\langle s_{\text {surf,model }} / \mathrm{g} \mathrm{kg}^{-1}\right.$ & 32.49 & 17.62 & 14.99 & 6.63 \\
\hline$\left\langle s_{\text {surf,model,evap }}\right\rangle / \mathrm{g} \mathrm{kg}^{-1}$ & 32.49 & 27.19 & 26.89 & 12.31 \\
\hline$\left\langle s_{\text {surf,model,precip }}\right\rangle / \mathrm{g} \mathrm{kg}^{-1}$ & - & - & 3.10 & 0.95 \\
\hline$-\left\langle s_{\text {surf,model }}\right\rangle^{2} Q_{\text {surf }} /\left(\mathrm{g} \mathrm{kg}^{-1}\right)^{2} \mathrm{~m}^{3} \mathrm{~s}^{-1}$ & 5258 & 1552 & 0.00 & 0.00 \\
\hline$-\left\langle s_{\text {surf,model,evap }}\right\rangle^{2} Q_{\text {evap }} /\left(\mathrm{g} \mathrm{kg}^{-1}\right)^{2} \mathrm{~m}^{3} \mathrm{~s}^{-1}$ & 5258 & 3697 & 3614 & 757.6 \\
\hline$-\left\langle s_{\text {surf,model,precip }}\right\rangle^{2} Q_{\text {precip }} /\left(\mathrm{g} \mathrm{kg}^{-1}\right)^{2} \mathrm{~m}^{3} \mathrm{~s}^{-1}$ & - & - & -48.00 & -4.51 \\
\hline$-\left\langle\left(s_{\text {surf,model }}\right)^{2}\right\rangle Q_{\text {surf }} /\left(\mathrm{g} \mathrm{kg}^{-1}\right)^{2} \mathrm{~m}^{3} \mathrm{~s}^{-1}$ & 5276 & 2169 & 0.00 & 0.00 \\
\hline$-\left\langle\left(s_{\text {surf,model,evap }}\right)^{2}\right\rangle Q_{\text {evap }} /\left(\mathrm{g} \mathrm{kg}^{-1}\right)^{2} \mathrm{~m}^{3} \mathrm{~s}^{-1}$ & 5276 & 3967 & 3914 & 958.4 \\
\hline$-\left\langle\left(s_{\text {surf,model,precip }}\right)^{2}\right\rangle Q_{\text {precip }} /\left(\mathrm{g} \mathrm{kg}^{-1}\right)^{2} \mathrm{~m}^{3} \mathrm{~s}^{-1}$ & - & - & -137.1 & -17.86 \\
\hline
\end{tabular}




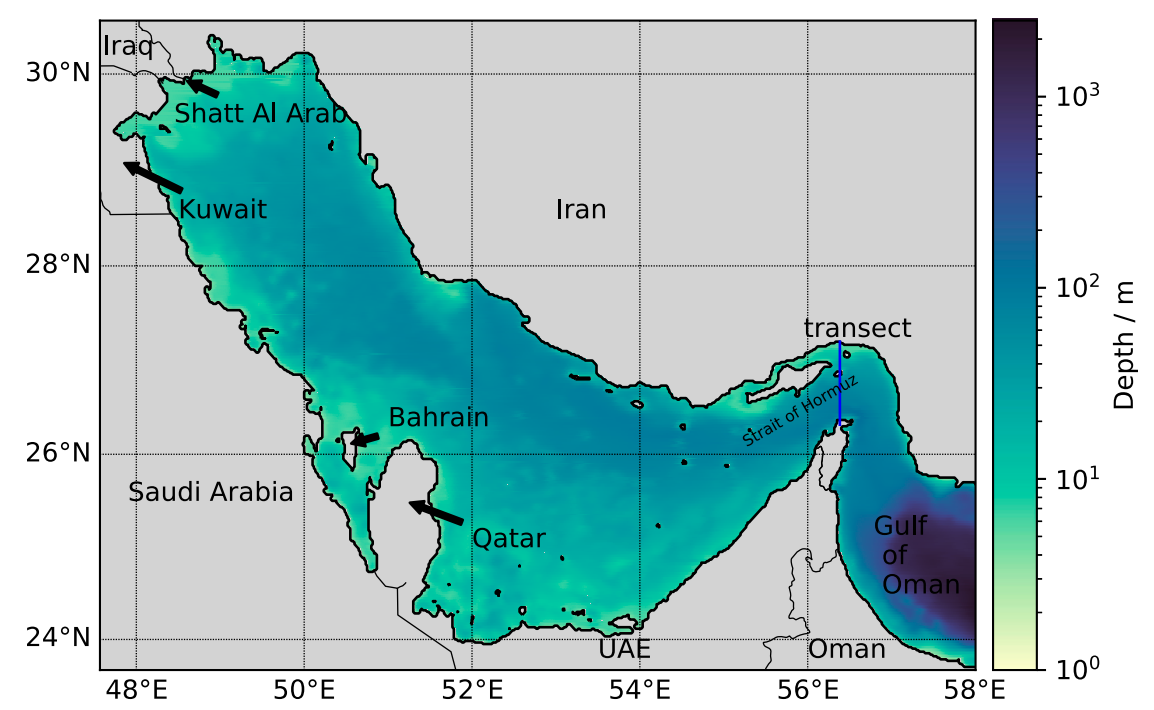

FIG. 3. Bathymetry and model domain of the Gulf: the shallow northwest and southern regions are bounded by a trench in the north, which is deepening toward the Strait of Hormuz. Outside the Strait of Hormuz, the depth increases to $\sim 2000 \mathrm{~m}$ (note the logarithmic color scale). The blue line denotes the transect across the Strait of Hormuz where the exchange flow is analyzed.

analysis as proposed by Lorenz et al. (2019) rather than an offline analysis of hourly output. We used 250 salinity bins from 0 to $50 \mathrm{~g} \mathrm{~kg}^{-1}$. The setup has a horizontal resolution of one nautical mile $(1 \mathrm{n} \mathrm{mi}=1.852 \mathrm{~km})$ based on ETOPO1 (Amante and Eakins 2009), a vertical resolution of 40 vertically adaptive coordinates (Hofmeister et al. 2010, 2011; Gräwe et al. 2015). It is forced with hourly meteorological data from the NCEP Climate Forecast System version 2 (CFSv2; Saha et al. 2011), and uses 3-hourly HYCOM boundary conditions (Chassignet et al. 2007) with tides from the Oregon State University Tidal Prediction Software (OTPS; Egbert and Erofeeva 2002) (30min resolution). For further details of the setup and the validation of the model, we refer to Lorenz et al. (2020).

The Persian Gulf is a semi-enclosed marginal sea with net freshwater loss due to evaporation. Its exchange flow is, therefore, following an inverse estuarine circulation. Although the evaporation is dominating the freshwater budget, there is an annual mean river discharge of $\approx 1600 \mathrm{~m}^{3} \mathrm{~s}^{-1}$ with the Shatt $\mathrm{Al} \mathrm{Arab}$ as the major contributor with a mean discharge of $1400 \mathrm{~m}^{3} \mathrm{~s}^{-1}$. The circulation of the Gulf is strongly dependent on the seasonal cycle. In winter, the Gulf is well mixed in most parts due to strong surface cooling, evaporation, winds, and its shallowness (mean depth $\approx 40 \mathrm{~m}$ ). In summer, the Gulf is stratified and a general counterclockwise circulation with large eddies ( $\sim 100-\mathrm{km}$ diameter) can be observed (Reynolds 1993; Kämpf and Sadrinasab 2006; Thoppil and Hogan 2010a; Yao and Johns 2010a; Pous et al. 2015). In contrast, in winter, the large eddies have dissipated and a lot of much smaller eddies ( $\sim 10-\mathrm{km}$ diameter) are occurring (Kämpf and Sadrinasab 2006; Yao and Johns 2010a; Pous et al. 2015).

The seasonality of the forcing translates into the salt mixing, see in Fig. 4, where the vertically integrated, monthly mean $\chi^{s}$ is shown $\left(\chi^{s}\right.$ includes both physical and numerical contributions). Four persistent salt mixing hotspots can be identified: the western shelf of the Gulf of Oman, the Strait of Hormuz, the river plume of the Shatt Al Arab, and the shallow zone north of Bahrain and west of Qatar.

The western shelf of Oman is the region where the Persian Gulf water stratifies into the Indian Ocean in around 250-m depth. The Gulf water interacts with the steep topography and forms eddies of mesoscale to submesoscale size (L'Hégaret et al. 2015; Vic et al. 2015; Morvan et al. 2019). This process is not sufficiently resolved in the hydrostatic model (Klingbeil and Burchard 2013) and the mixing in our simulation is explained by numerical mixing due to internal pressure gradient errors within the terrain-following coordinates (Shchepetkin and McWilliams 2003).

The hotspot located in the Strait of Hormuz is where the exchange flow is occurring, see Fig. 5 for the mean salinity and mean velocity structure in summer and winter, respectively. The high mixing there is related to topographic features in the channel, strong tidal currents, and eddy activity (Swift and Bower 2003), which mix the saline outflowing water with the inflowing water. Along the Iranian coast in the Strait, there is only Indian Ocean water of almost constant salinity (see Fig. 5), which explains the low salt mixing values as there are only small salinity gradients. West of the Strait there is more mixing occurring in fall when the buoyancy loss due to the atmospheric forcing occurs. Almost all year there is a line of high mixing which is the front between the Iranian Coastal Jet of Indian Ocean Surface Water and the more saline Persian Gulf water (Kämpf and Sadrinasab 2006).

Two more mixing hotspots are located further inside the Gulf: the Shatt Al Arab river plume area and the area north of Bahrain and west of Qatar. The high mixing values are explained by the strong vertical salinity gradients in those 


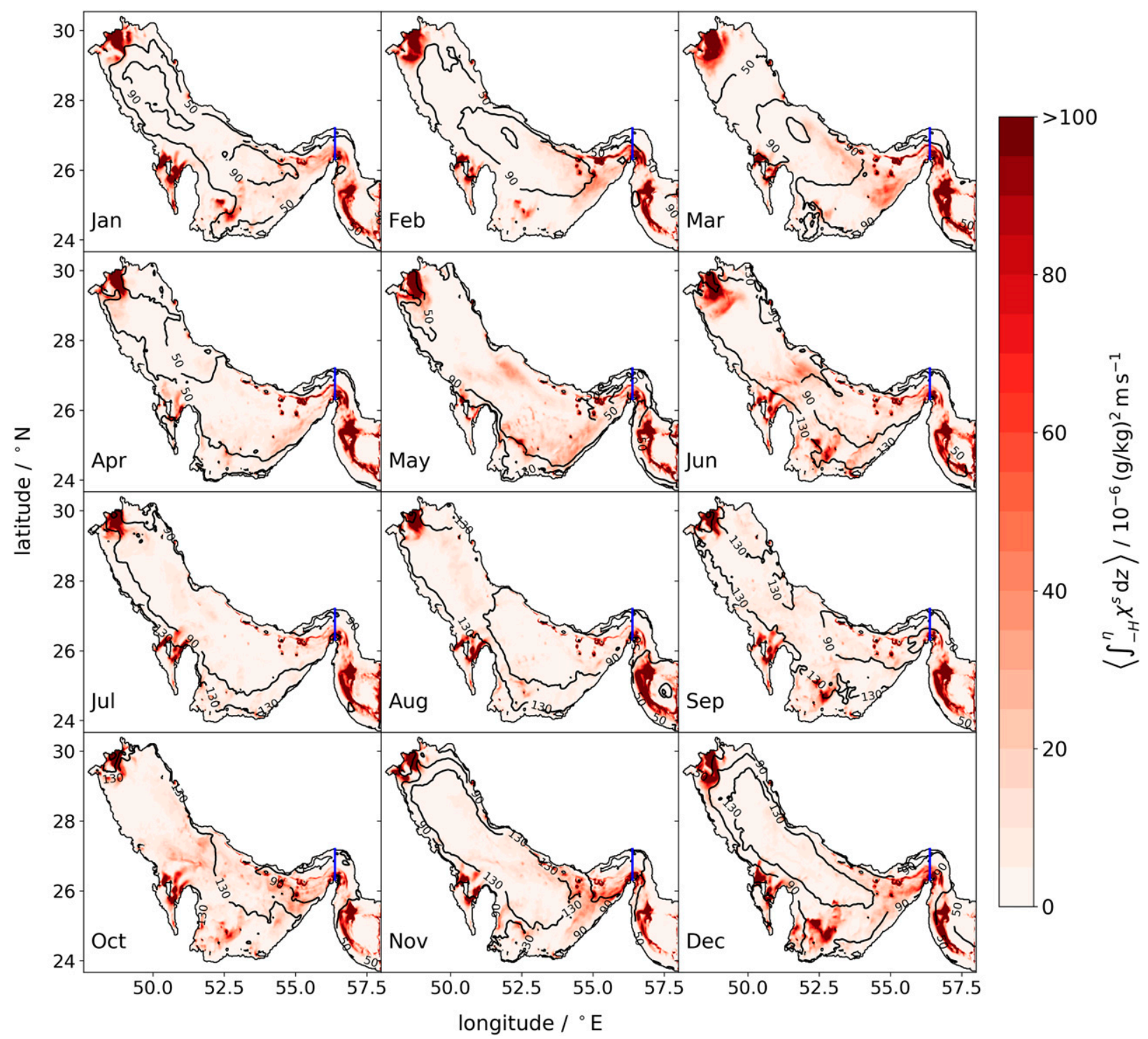

FIG. 4. Monthly mean mixing map of the Gulf for 2011: color coded is the vertically integrated local salt mixing $\chi^{s}$, see Eq. (12). The black contour shows the local surface salinity square flux in $10^{-6}\left(\mathrm{~g} \mathrm{~kg}^{-1}\right)^{2} \mathrm{~m} \mathrm{~s}^{-1}$, see also Eq. (24). The blue line denotes the transect across the Strait of Hormuz where the exchange flow is analyzed.

regions. The fresh, thus buoyant water of the Shatt Al Arab stratifies over the saline Gulf water forming large vertical salinity gradients which are mixed, for example, by tidal currents. The vertical salinity gradients north of Bahrain are created by a dense gravity current flowing into the Gulf's interior. Hypersaline water of salinities greater than $50 \mathrm{~g} \mathrm{~kg}^{-1}$ is formed in the shallow south of Bahrain, which stratifies below the adjacent Gulf water. Although dense water is formed in this region, it is negligible as a source of outflowing Persian Gulf Water (Lorenz et al. 2020).

Besides these persistent hotspots, seasonality can be observed also in other parts of the Gulf. The vertically integrated salt mixing is smaller in winter (JFM) and summer (JAS) than in spring (AMJ) and fall (OND). The explanation is found in the vertical structure of the Gulf: in winter most regions of the Gulf are well mixed, i.e., there are no salinity gradients to be mixed. In spring, stratification and the basinwide circulation start to form, which creates shear and therefore salt mixing. In summer, stratification is strongest, inhibiting vertical mixing. In fall the stratification is mixed away due to surface cooling, strong evaporation, and winds, reflected in the high local mixing values.

The surface salinity square transport is strongest in November and weakest in March, see contours in Fig. 4. From March onward the transport grows from the shallow coasts offshore until September, before it decreases again starting from the shallows. The shallow areas have higher surface salinities (Reynolds 1993; Kämpf and Sadrinasab 2006; Yao and 


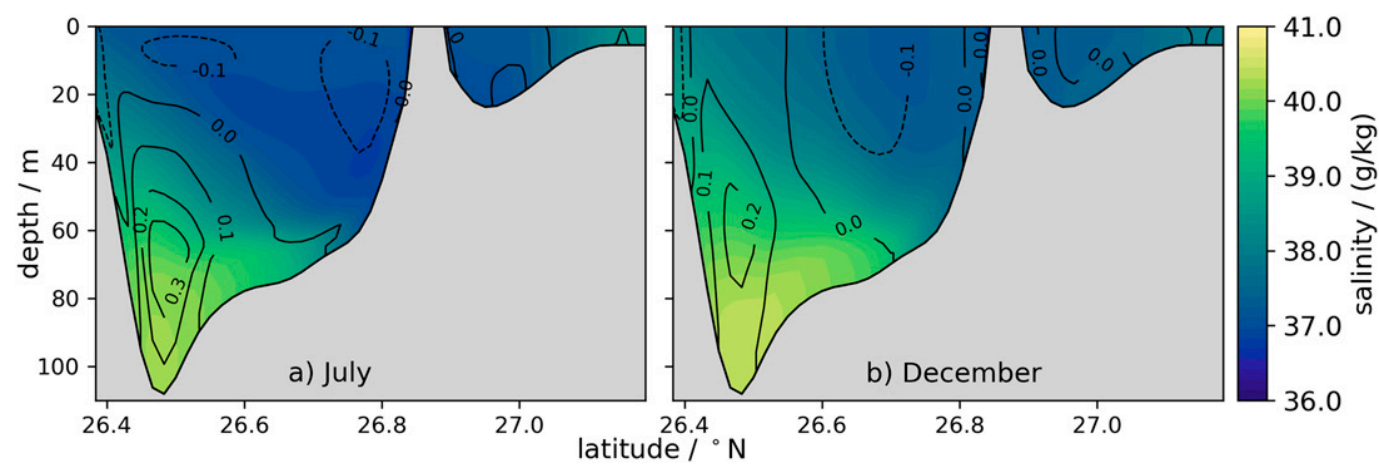

FIG. 5. Monthly mean structure of salinity (color) and velocity (solid contours: eastward; dashed contours: westward) for (a) July and (b) December along the analyzed transect in the Strait of Hormuz, see Fig. 3 for the location: the interface between the outflowing, hypersaline water and the inflowing water is tilted due to Earth's rotation. In July, when the vertical stratification is stronger, the tilting angle is smaller, whereas in December, when the stratification is weaker, the tilting angle is larger, causing the outflow to also occur near the surface at the southern coast.

Johns 2010a; Pous et al. 2015) which combined with the dry easterly to southeasterly winds cause this spatial distribution.

It is well known that the outflowing water is formed in late fall and winter in the northwest and southern shallows, which then propagates as a bottom current to the Strait of Hormuz (Reynolds 1993; Kämpf and Sadrinasab 2006; Yao and Johns 2010b; Pous et al. 2015; Lorenz et al. 2020). Lorenz et al. (2020) show that in late July/early August a regime shift in the outflowing water occurs. From February to August, most outflowing water in the Strait of Hormuz, except entrained surface waters, originated in the southern shallows in fall and winter. The propagation time is $2-3$ months. From August onward most outflowing water was formed in the northwest during fall and winter, more than 6 months prior. During this time period, water from the southern shallows is not dense enough to become part of the bottom water (Yao and Johns 2010b). This shift in water masses is reflected in the increase of the salinity of the outflow in early August.

A time series for 2011 of the exchange flow properties across the transect in the Strait of Hormuz, see Fig. 3 for the location and Fig. 5 for the spatial structure of the exchange flow, reflects the described seasonality (see Fig. 6). The volume exchange is highly variable at time scale of a few days. On a weekly time scale, a spring-neap cycle can be observed, especially in the outflow. The inflow is near the surface and therefore affected more by winds. On seasonal time scales, we find that the volume exchange is stronger in the first half of the year, when the well-mixed state transitions into the stratified state, than the second half where increased vertical mixing weakens the exchange flow (Yao and Johns 2010b; Pous et al. 2015; Lorenz et al. 2020). The salinity of the inflow $s_{\text {in }}$ is $\sim 37 \mathrm{~g} \mathrm{~kg}^{-1}$ whereas the salinity of the outflow follows the seasonal cycle described before (see Fig. 6b). The salinity of the outflow $s_{\text {out }}$ decreases from March to July since the salinity of the surface waters inside the Persian Gulf decreases during that time period (increasing salinity stratification inside the Gulf due to more inflow). On the dense water's path from its origin to the transect, it is entrained with the less saline surface water. The increase of $s_{\text {out }}$ afterward is due to the arrival of dense winter water formed in the north (Lorenz et al. 2020). For this simulation, $\left(s^{2}\right)_{\text {in,out }} \approx\left(s_{\text {in,out }}\right)^{2}$, and both are therefore not shown. The basin-averaged model surface salinity, Fig. 6b, shows a seasonal cycle with the lowest salinities in summer and highest in winter (Kämpf and Sadrinasab 2006). The surface salinity bulk value, $s_{\text {surf }}$ defined in Eq. (36), is more variable than the model surface salinity and is highest in summer and lowest in winter, contrary to the model surface salinity. This is due to the weighting of the model surface salinity with the evaporation rate which is most of the year higher near the shallow coasts where the highest surface salinities are found.

The described seasonality of the local salt mixing is visualized more clearly in the time series of the mixing $M_{e}$, see Fig. 6d. For this simulation the constancy assumption (33) shows only a small error, since the graphs of the bulk salinities and bulk salinity squares show the same temporal evolution, proving that for this exchange flow $s_{\text {in }}^{2} \approx\left(s^{2}\right)_{\text {in }}$ and $s_{\text {out }}^{2} \approx\left(s^{2}\right)_{\text {out }}$. The mixing is highly variable on a time scale of a few days which is expected when the exchange flow in itself is highly variable on that time scale. The volume budget on this time scale is dominated by the storage term $\delta V$, see Fig. 6c, as it is one order of magnitude larger than the surface freshwater forcing $Q_{\text {surf }}$, see Fig. 6e, which in turn is one order of magnitude larger than the river discharge $Q_{r}$. The salinity storage $\delta S$ and salinity square storage $\delta S^{2}$ are proportionally larger than $\delta V$ (not shown here). Due to the dominant storage terms, we do not show the mixing relations (34) and (35) in Fig. 6d as these assumptions are clearly not valid for a time series of daily values. The frequent changes are due to tides and wind events (Thoppil and Hogan 2009, 2010b). The wind events are called Shamal which brings dry air to the Gulf leading especially in fall to a great heat loss and high evaporation rates, as seen in November and December Fig. 6e and is investigated in detail by Thoppil and Hogan (2010b). On a weekly time scale, the mixing is a result of surface transports, e.g., the higher mixing in June due to the high $F_{\text {surf }}^{s^{2}}$ and high mixing periods in October/November, plus the effects of spring-neap variations. 

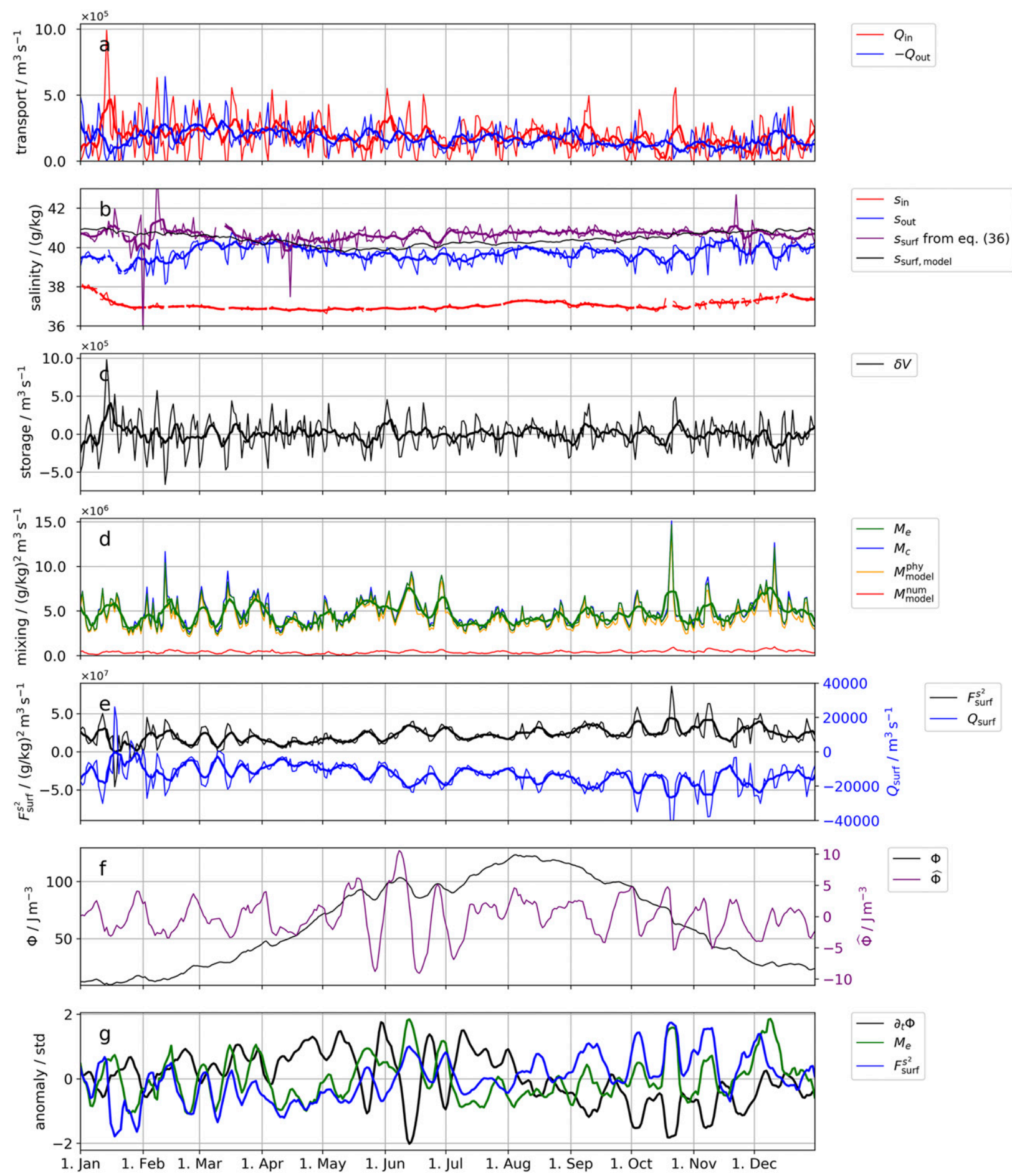

FIG. 6. Time series of the daily exchange flow and mixing quantities for 2011: (a) bulk volume transport values, (b) bulk salinities of the exchange flow and surface salinities, Eq. (36), and model salinity, (c) volume storage $\delta V$, (d) mixing computed from the exchange flow bulk values using relations (32) and (33), and physical, numerical mixing of the model, (e) surface freshwater transport $Q_{\text {surf }}$ and surface salinity square transport $F_{\text {surf }}^{s^{2}}$, (f) potential energy anomaly (PEA) $\Phi$ (Simpson et al. 1978) and $\Phi$ without the seasonal signal, $\hat{\Phi}$, and (g) the temporal change of $\Phi, \partial_{t} \Phi, M_{e}$, and $F_{\text {surf }}^{s^{2}}$ (anomaly from the annual mean and scaled with the respective standard deviation). The thick lines are smoothed with a 1-week running mean filter. Note the different scaling of the $y$ axis in each panel. If there is a blank in the time series, e.g., in (b), then the respective inflow or outflow is zero and the bulk values are zero as well. Further note that the bulk salinity squares are very closely following the squared bulk salinities. The annual results of the mixing relation are listed in Table 4. 
The effects of the spring-neap variability on $M$ are shown by Wang et al. (2017) for the Hudson River and by MacCready et al. (2018) for an idealized estuary. The strongest signal is found to be time scales between 14 and 17 days, which is the time scale of the spring-neap cycle, but also the length of high/low evaporation over the Gulf (see Fig. 6e).

As a measure of stratification and to show its relation to mixing, we used the potential energy anomaly (PEA) $\Phi($ Simpson et al. 1978) (see Fig. 6f). For a well-mixed state $\Phi=$ 0 , whereas $\Phi>0$ indicates stratification. The high values of PEA (averaged over the Gulf) in Fig. $6 f$ in summer and low values in winter indicate seasonal stratification. PEA further changes significantly on a biweekly time scale, which is visible more clearly for $\hat{\Phi}$, where the seasonal signal is removed by subtracting the running 30-day mean from $\Phi$. The changes of $\hat{\Phi}$ are due to mixing. The temporal change of $\Phi, \partial_{t} \Phi$, is well (negatively) correlated to the mixing $M$, see Fig. $6 \mathrm{~g}$ where the anomalies of $\partial_{t} \Phi, M_{e}$, and $F_{\text {surf }}^{s^{2}}$ from their respective annual mean values, scaled by their respective standard deviation, are shown. When there is high mixing, $\partial_{t} \Phi$ is negative and vice versa, indicating that mixing reduces stratification and the absence of mixing allows stratification to form or increase. Furthermore, Fig. $6 \mathrm{~g}$ suggests that most of the variation in $M_{e}$ is due to $F_{\text {surf }}^{s^{2}}$, which is more pronounced in fall and winter than spring and summer.

On seasonal time scales the storage terms minimize and the seasonality of the exchange flow and the forcing is visible. The volume storage is orders of magnitude smaller than the freshwater forcing, see Table 4. The mixing is low from January to April, increases from May to July, decreases until October before reaching its maximum in November and December. This seasonal mixing cycle is modulated with the seasonal surface salinity square transport $F_{\text {surf }}^{s^{2}}$, see Fig. 6e, which shows strong variations on scale of $\sim 16$ days. The analyzed time series in this study is too short to investigate longer time scales,
TABLE 4. Results of the mixing analysis for the whole Persian Gulf in 2011: all annual mean variables needed to compute the mixing with relations (32)-(35) are listed below.

\begin{tabular}{lc}
\hline \multicolumn{1}{c}{ Variable/unit } & Value \\
\hline$s_{\text {in }} / \mathrm{g} \mathrm{kg}^{-1}$ & 36.98 \\
$s_{\text {out }} / \mathrm{g} \mathrm{kg}^{-1}$ & 39.93 \\
{$\left[\left(s^{2}\right)_{\mathrm{in}}\right]^{1 / 2} / \mathrm{g} \mathrm{kg}^{-1}$} & 36.98 \\
{$\left[\left(s^{2}\right)_{\text {out }}\right]^{1 / 2} / \mathrm{g} \mathrm{kg}^{-1}$} & 39.93 \\
$s_{\text {surf }}$ with Eq. $(36) / \mathrm{g} \mathrm{kg}^{-1}$ & 40.68 \\
$\left\langle s_{\text {surf,model }}\right\rangle / \mathrm{g} \mathrm{kg}^{-1}$ & 40.43 \\
$\delta V / \mathrm{m}^{3} \mathrm{~s}^{-1}$ & -62 \\
$\delta S /\left(\mathrm{g} \mathrm{kg}^{-1}\right) \mathrm{m}^{3} \mathrm{~s}^{-1}$ & -9887 \\
$\delta S^{2} /\left(\mathrm{g} \mathrm{kg}^{-1}\right)^{2} \mathrm{~m}^{3} \mathrm{~s}^{-1}$ & -568866 \\
$Q_{r} / \mathrm{m}^{3} \mathrm{~s}^{-1}$ & 1691 \\
$Q_{\text {surf }} / \mathrm{m}^{3} \mathrm{~s}^{-1}$ & -13340 \\
$F_{\text {surf }}^{s^{2}} /\left(\mathrm{g} \mathrm{kg}^{-1}\right)^{2} \mathrm{~m}^{3} \mathrm{~s}^{-1}$ & 22080406 \\
$-\left\langle s_{\text {surf, model }}\right\rangle^{2} Q_{\mathrm{surf}} /\left(\mathrm{g} \mathrm{kg}^{-1}\right)^{2} \mathrm{~m}^{3} \mathrm{~s}^{-1}$ & 21810458 \\
$M_{e} /\left(\mathrm{g} \mathrm{kg}^{-1}\right)^{2} \mathrm{~m}^{3} \mathrm{~s}^{-1}$ & 4714700 \\
$M_{c} /\left(\mathrm{g} \mathrm{kg}^{-1}\right)^{2} \mathrm{~m}^{3} \mathrm{~s}^{-1}$ & 4782332 \\
$M_{p} /\left(\mathrm{g} \mathrm{kg}^{-1}\right)^{2} \mathrm{~m}^{3} \mathrm{~s}^{-1}$ & 4815712 \\
$M_{c p} /\left(\mathrm{g} \mathrm{kg}^{-1}\right)^{2} \mathrm{~m}^{3} \mathrm{~s}^{-1}$ & 4882160 \\
$M_{\text {model }}^{\text {tot }} /\left(\mathrm{g} \mathrm{kg}^{-1}\right)^{2} \mathrm{~m}^{3} \mathrm{~s}^{-1}$ & 4714700 \\
$M_{\text {model }}^{\text {phy }} /\left(\mathrm{g} \mathrm{kg}^{-1}\right)^{2} \mathrm{~m}^{3} \mathrm{~s}^{-1}$ & 4309199 \\
$M_{\text {model }}^{\text {num }} /\left(\mathrm{g} \mathrm{kg}^{-1}\right)^{2} \mathrm{~m}^{3} \mathrm{~s}^{-1}$ & 405501 \\
\hline
\end{tabular}

but as interannual variability exists in the exchange flow of the Gulf (Pous et al. 2015; Lorenz et al. 2020; Campos et al. 2020), the mixing should vary on interannual time scales. From the results of Lorenz et al. (2020) we would expect that the mixing variations at this time scale should be a lot smaller than the variability of the diurnal and biweekly time scales.

The annual mean mixing of the Gulf in this simulation is $M$ $\approx 4.7 \times 10^{6}\left(\mathrm{~g} \mathrm{~kg}^{-1}\right)^{2} \mathrm{~m}^{3} \mathrm{~s}^{-1}$; see Table 4 for the exact value. For this simulation the relative errors of the different assumptions are

$$
\begin{array}{r}
\text { constancy: }\left|\frac{M_{c}-M_{e}}{M_{e}}\right|=1.4 \%, \\
\text { periodicity: }\left|\frac{M_{p}-M_{e}}{M_{e}}\right|=2.1 \%, \\
\text { constancy and periodicity: }\left|\frac{M_{c p}-M_{e}}{M_{e}}\right|=3.6 \%, \\
\text { approximated } F_{\text {surf }}^{s^{2}}:\left|\frac{-\left\langle s_{\text {surf,model }}\right\rangle^{2} Q_{\text {surf }}-F_{\text {surf }}^{s^{2}}}{F_{\text {surf }}^{s^{2}}}\right|=1.2 \%, \\
\text { constancy, periodicity, and approximated } F_{\text {surf }}^{s^{2}}:\left|\frac{s_{\text {in }} s_{\text {out }}\left(Q_{r}+Q_{\text {surf }}\right)-\left\langle s_{\text {surf,model }}\right\rangle^{2} Q_{\text {surf }}-M_{e} \mid=2.2 \%,}{M_{e}}\right|=2 .
\end{array}
$$

where $s_{\text {surf,model }}$ is the mean surface salinity of the model. The errors of all mixing relations and also the approximation of the exact $F_{\text {surf }}^{s^{2}}$ are small. Based on these results the mixing of the Persian Gulf on long time scales can be well approximated by Eq. (37), where $s_{\text {surf }}$ can be the long-term average surface salinity, instead of the more complex definition (36).

Decomposing (37) into riverine and surface freshwater contributions, we find that both contribute almost equally to the total mixing: 


$$
\begin{aligned}
M_{\text {river }} & =s_{\text {in }} s_{\text {out }} Q_{r} \approx 2.5 \times 10^{6}\left(\mathrm{~g} \mathrm{~kg}^{-1}\right)^{2} \mathrm{~m}^{3} \mathrm{~s}^{-1} \\
M_{\text {surface }} & =\left[s_{\text {in }} s_{\text {out }}-\left(s_{\text {surf }}\right)^{2}\right] Q_{\text {surf }} \approx 2.1 \times 10^{6}\left(\mathrm{~g} \mathrm{~kg}^{-1}\right)^{2} \mathrm{~m}^{3} \mathrm{~s}^{-1}
\end{aligned}
$$

This is an interesting result, as the freshwater forcing due to evaporation is almost a factor of 10 greater than the river discharge. This makes sense, as the gradients associated with these processes are very different: for the surface mixing, the salinity gradients are very small but scaled with a large area. For the mixing due to river runoff, the gradients are large but confined to a small area. Assuming the freshwater has to be mixed approximately to the mean salinity of the Gulf (>40 $\mathrm{g} \mathrm{kg}^{-1}$; Ibrahim et al. 2020), and following the isohaline theory by Burchard (2020), the long-term averaged mixing due to river runoff integrated over the volume bounded by the river and the $40 \mathrm{~g} \mathrm{~kg}^{-1}$ isohaline has to be $M=\left(40 \mathrm{~g} \mathrm{~kg}^{-1}\right)^{2} Q_{r}$. This means that even though river discharge is almost an order of magnitude smaller than evaporation, the riverine mixing is high due to the large salinity range the freshwater has to be entrained through.

\section{Discussion and conclusions}

In this study, we derived a mixing relation that is valid for all estuaries since it includes surface freshwater fluxes. Crucial to this relation is the newly introduced integrated surface salinity square transport due to precipitation and evaporation, $F_{\text {surf }}^{s^{2}}$. This term is essential when describing estuaries where the surface freshwater contributions by precipitation and evaporation cannot be neglected or are the main driver of the circulation, like in an inverse estuary. On the other hand, when the river discharge dominates the volume budget, the surface contributions may be neglected, resulting in the mixing relations presented in MacCready et al. (2018) and Burchard et al. (2019).

We showed that the extended mixing relation (32) exactly obeys the mixing directly diagnosed during the model simulation, proving the validity of this relation. We further analyzed the validity of approximated relations: (i) assuming constancy, i.e., $\left(s^{2}\right)_{\text {in }}=\left(s_{\text {in }}\right)^{2}$ and $\left(s^{2}\right)_{\text {out }}=\left(s_{\text {out }}\right)^{2}$, relation (33); (ii) assuming periodicity/long-term averaging, i.e., vanishing storage terms, relation (34); (iii) assuming both at the same time, relation (35). We performed four two-dimensional idealized simulations with different freshwater forcing to exemplify the mixing relations (see section $4 \mathrm{~b}$ ). From the performed idealized simulations we cannot generalize the errors of the assumptions as these seem to be setup specific. For example, the constancy assumption fails for experiment A (only evaporation) but is a good approximation for experiments $\mathrm{B}$ (evaporation + river discharge) and $\mathrm{C}$ (evaporation + precipitation). It is desirable to approximate the newly introduced term for the integrated surface salinity square transport $F_{\text {surf }}^{s^{2}}$, as this term requires a high temporal and spatial resolution of surface salinity, precipitation, and evaporation rates. Our results show that it can be approximated with

$$
F_{\text {surf }}^{s^{2}} \approx-\left(s_{\text {surf }}\right)^{2} Q_{\text {surf }},
$$

when either precipitation or evaporation dominate the surface freshwater flux, i.e., $P \gg E$ or $E \gg P$, as it is in experiment $\mathrm{A}$ (evaporation, no precipitation), and also the Persian Gulf simulation $(E \gg P)$ (see section 4 c). When both are equal, $E \approx$ $P$, or occur in different areas, evaporation and precipitation have to be evaluated separately with the respective surface salinities, see Eq. (47). We showed this in experiments C (evaporation + precipitation) and $\mathrm{D}$ (evaporation + precipitation + river discharge), where the net surface freshwater transport is zero. Based on these findings, we conclude that if either $E$ or $P$ dominate the surface freshwater budget and if the averaging period is long enough, the mixing can be sufficiently approximated with Eq. (37),

$$
M \approx M_{c p}=s_{\text {in }} s_{\text {out }}\left(Q_{r}+Q_{\text {surf }}\right)-s_{\text {surf,model }}^{2} Q_{\text {surf }},
$$

with $s_{\text {surf,model }}$ being the simulated long-term mean, estuarywide averaged surface salinity instead of the surface salinity bulk value we defined in Eq. (36) which is defined using the exact $F_{\text {surf }}^{2}$. For the annual Persian Gulf simulation the error of relation (52) is only $2.2 \%$ (see section $4 c$ ), proving that the relation is a reliable quantification method. For other applications outside modeling, $s_{\text {surf,model }}$ may also be replaced by direct observations of the surface salinity, if available. Relation (52) further allows decomposing the mixing contributions from river runoff and cross-surface transports. For the Persian Gulf, with a total mixing of $\sim 4.7 \times 10^{6}\left(\mathrm{~g} \mathrm{~kg}^{-1}\right)^{2} \mathrm{~m}^{3} \mathrm{~s}^{-1}$, the two contributions are almost equal, despite the order of magnitude difference in freshwater forcing, $\left|Q_{\text {surf }}\right| \approx 10\left|Q_{r}\right|$.

In general, the separate quantification of mixing due to river runoff and mixing due to cross-surface freshwater transports may help to advance the understanding of estuarine dynamics in future studies, e.g., when working with tropical estuaries, where the freshwater forcing may shift from wet to dry season (Wolanski 1986; Valle-Levinson and Bosley 2003) and with it the mixing contributions.

We have shown that for the Persian Gulf changes in freshwater forcing immediately modify the mixing $M$, i.e., evaporation events in Fig. 6g. Other sources of immediate changes in mixing could be discharge events (Lemagie and Lerczak 2020) and wind events (Lange et al. 2020). Some remaining open questions not only for the Persian Gulf but also for any estuary are the following: how do these spatial and temporal changes in mixing interact and change the circulation and salinity fields? When are these changes detectable in the properties of the exchange flow, e.g., $s_{\text {in }}$ and $s_{\text {out }}$ ? We think that the presented mixing relations as well as tools like the direct analysis of salinity variance (Li et al. 2018; Warner et al. 2020), but also an isohaline mixing analysis (Burchard 2020; Burchard et al. 2021) are suitable tools to answer these questions.

Acknowledgments. The authors want to thank the two anonymous reviewers for their constructive feedback. This study was conducted within the framework of the Research Training Group "Baltic TRANSCOAST" funded by the Deutsche Forschungsgemeinschaft (DFG, German Research Foundation)-GRK 2000 (www.baltic-transcoast.uni-rostock.de). This is Baltic TRANSCOAST publication GRK2000/0036. 
H.B. and K.K. were further supported by the Collaborative Research Centre TRR 181 on Energy Transfer in Atmosphere and Ocean funded by the German Research Foundation (project 274762653). The numerical simulations were performed with resources provided by the North-German Supercomputing Alliance (HLRN). Most of the analysis work was performed by computers financed by PROSO (FKZ: 03F0779A).

Data availability statement. The data of the annual Persian Gulf simulation can be found here: https://www.io-warnemuende. de/marvin-lorenz-publications.html. Please contact one of the authors if you are interested in the analysis scripts or the idealized simulations.

\section{REFERENCES}

Amante, C., and B. W. Eakins, 2009: ETOPO1 1 arc-minute global relief model: Procedures, data sources and analysis. NOAA Tech. Memo NESDIS NGDC-24, 19 pp., https://www.ngdc.noaa.gov/ $\mathrm{mgg} / \mathrm{global} / \mathrm{relief} / \mathrm{ETOPO} 1 /$ docs/ETOPO1.pdf.

Beron-Vera, F., J. Ochoa, and P. Ripa, 1999: A note on boundary conditions for salt and freshwater balances. Ocean Modell., 1, 111-118, https://doi.org/10.1016/S1463-5003(00)00003-2.

Burchard, H., 2020: A universal law of estuarine mixing. J. Phys. Oceanogr., 50, 81-93, https://doi.org/10.1175/JPO-D-19-0014.1.

—_, and K. Bolding, 2001: Comparative analysis of four secondmoment turbulence closure models for the oceanic mixed layer. J. Phys. Oceanogr., 31, 1943-1968, https://doi.org/ 10.1175/1520-0485(2001)031<1943:CAOFSM>2.0.CO;2.

$\longrightarrow$, and —, 2002: GETM - A general estuarine transport model: Scientific documentation. European Commission Tech. Rep. EUR 20253 EN, 157 pp.

— and numerically induced mixing in ocean models. Ocean Modell., 20, 293-311, https://doi.org/10.1016/j.ocemod.2007.10.003.

_- F. Janssen, K. Bolding, L. Umlauf, and H. Rennau, 2009: Model simulations of dense bottom currents in the western Baltic Sea. Cont. Shelf Res., 29, 205-220, https://doi.org/ 10.1016/j.csr.2007.09.010.

- , and Coauthors, 2018: The Knudsen theorem and the total exchange flow analysis framework applied to the Baltic Sea. Prog. Oceanogr., 165, 268-286, https://doi.org/10.1016/ j.pocean.2018.04.004.

__ X. Lange, K. Klingbeil, and P. MacCready, 2019: Mixing estimates for estuaries. J. Phys. Oceanogr., 49, 631-648, https://doi.org/10.1175/JPO-D-18-0147.1.

- , U. Graewe, K. Klingbeil, N. Koganti X. Lange, and M. Lorenz, 2021: Effective diahaline diffusivities in estuaries. J. Adv. Model. Earth Syst., 13, e2020MS002307, https://doi.org/ 10.1029/2020MS002307.

Campos, E. J., A. L. Gordon, B. Kjerfve, F. Vieira, and G. Cavalcante, 2020: Freshwater budget in the Persian (Arabian) Gulf and exchanges at the Strait of Hormuz. PLOS ONE, 15, e0233090, https://doi.org/10.1371/journal.pone.0233090.

Chassignet, E. P., H. E. Hurlburt, O. M. Smedstad, G. R. Halliwell, P. J. Hogan, A. J. Wallcraft, R. Baraille, and R. Bleck, 2007: The HYCOM (Hybrid Coordinate Ocean Model) data assimilative system. J. Mar. Syst., 65, 60-83, https://doi.org/ 10.1016/j.jmarsys.2005.09.016.

Egbert, G. D., and S. Y. Erofeeva, 2002: Efficient inverse modeling of barotropic ocean tides. J. Atmos. Oceanic
Technol., 19, 183-204, https://doi.org/10.1175/1520-0426(2002) $019<0183$ :EIMOBO $>2.0 . C O ; 2$.

Gräwe, U., P. Holtermann, K. Klingbeil, and H. Burchard, 2015: Advantages of vertically adaptive coordinates in numerical models of stratified shelf seas. Ocean Modell., 92, 56-68, https://doi.org/10.1016/j.ocemod.2015.05.008.

Hofmeister, R., H. Burchard, and J.-M. Beckers, 2010: Nonuniform adaptive vertical grids for 3D numerical ocean models. Ocean Modell., 33, 70-86, https://doi.org/10.1016/ j.ocemod.2009.12.003.

_ , J.-M. Beckers, and H. Burchard, 2011: Realistic modelling of the exceptional inflows into the central Baltic Sea in 2003 using terrain-following coordinates. Ocean Modell., 39, 233-247, https://doi.org/10.1016/j.ocemod.2011.04.007.

Ibrahim, H. D., P. Xue, and E. A. B. Eltahir, 2020: Multiple salinity equilibria and resilience of Persian/Arabian Gulf basin salinity to brine discharge. Front. Mar. Sci., 7, 573, https://doi.org/ 10.3389/fmars.2020.00573.

Kämpf, J., and M. Sadrinasab, 2006: The circulation of the Persian Gulf: A numerical study. Ocean Sci., 2, 27-41, https://doi.org/ 10.5194/os-2-27-2006.

Klingbeil, K., and H. Burchard, 2013: Implementation of a direct nonhydrostatic pressure gradient discretisation into a layered ocean model. Ocean Modell., 65, 64-77, https://doi.org/ 10.1016/j.ocemod.2013.02.002.

—, M. Mohammadi-Aragh, U. Gräwe, and H. Burchard, 2014: Quantification of spurious dissipation and mixing-discrete variance decay in a finite-volume framework. Ocean Modell., 81, 4964, https://doi.org/10.1016/j.ocemod.2014.06.001.

— F. Lemarié, L. Debreu, and H. Burchard, 2018: The numerics of hydrostatic structured-grid coastal ocean models: State of the art and future perspectives. Ocean Modell., 125, 80-105, https://doi.org/10.1016/j.ocemod.2018.01.007.

_ J. Becherer, E. Schulz, H. E. de Swart, H. M. Schuttelaars, A. Valle-Levinson, and H. Burchard, 2019: Thicknessweighted averaging in tidal estuaries and the vertical distribution of the eulerian residual transport. J. Phys. Oceanogr., 49, 1809-1826, https://doi.org/10.1175/JPO-D-18-0083.1.

Knudsen, M., 1900: Ein hydrographischer Lehrsatz. Ann. Hydrogr. Marit. Meteor., 28, 316-320.

Lange, X., K. Klingbeil, and H. Burchard, 2020: Inversions of estuarine circulation are frequent in a weakly tidal estuary with variable wind forcing and seaward salinity fluctuations. J. Geophys. Res. Oceans, 125, e2019JC015789, https://doi.org/ 10.1029/2019JC015789.

Lemagie, E., and J. Lerczak, 2020: The evolution of a buoyant river plume in response to a pulse of high discharge from a small midlatitude river. J. Phys. Oceanogr., 50, 1915-1935, https:// doi.org/10.1175/JPO-D-19-0127.1.

L'Hégaret, P., R. Duarte, X. Carton, C. Vic, D. Ciani, R. Baraille, and S. Corréard, 2015: Mesoscale variability in the Arabian Sea from HYCOM model results and observations: Impact on the Persian Gulf Water path. Ocean Sci., 11, 667-693, https:// doi.org/10.5194/os-11-667-2015.

Li, X., W. R. Geyer, J. Zhu, and H. Wu, 2018: The transformation of salinity variance: A new approach to quantifying the influence of straining and mixing on estuarine stratification. J. Phys. Oceanogr., 48, 607-623, https://doi.org/10.1175/JPOD-17-0189.1.

Lorenz, M., K. Klingbeil, P. MacCready, and H. Burchard, 2019: Numerical issues of the total exchange flow (TEF) analysis framework for quantifying estuarine circulation. Ocean Sci., 15, 601-614, https://doi.org/10.5194/os-15-601-2019. 
- , and H. Burchard, 2020: Numerical study of the exchange flow of the Persian Gulf using an extended total exchange flow analysis framework. J. Geophys. Res. Oceans, $\mathbf{1 2 5}$, e2019JC015527, https://doi.org/10.1029/2019JC015527.

MacCready, P., 2011: Calculating estuarine exchange flow using isohaline coordinates. J. Phys. Oceanogr., 41, 1116-1124, https://doi.org/10.1175/2011JPO4517.1.

—, W. Rockwell Geyer, and H. Burchard, 2018: Estuarine exchange flow is related to mixing through the salinity variance budget. J. Phys. Oceanogr., 48, 1375-1384, https://doi.org/ 10.1175/JPO-D-17-0266.1.

Morvan, M., P. L'Hégaret, X. Carton, J. Gula, C. Vic, C. de Marez, M. Sokolovskiy, and K. Koshel, 2019: The life cycle of submesoscale eddies generated by topographic interactions. Ocean Sci., 15, 1531-1543, https://doi.org/10.5194/os-151531-2019.

Nash, J. D., and J. N. Moum, 2002: Microstructure estimates of turbulent salinity flux and the dissipation spectrum of salinity. J. Phys. Oceanogr., 32, 2312-2333, https://doi.org/10.1175/ 1520-0485(2002)032<2312:MEOTSF $>2.0 . \mathrm{CO} ; 2$.

Nurser, A. J. G., and S. M. Griffies, 2019: Relating the diffusive salt flux just below the ocean surface to boundary freshwater and salt fluxes. J. Phys. Oceanogr., 49, 2365-2376, https://doi.org/ 10.1175/JPO-D-19-0037.1.

Pietrzak, J., 1998: The use of TVD limiters for forward-in-time upstream-biased advection schemes in ocean modeling. Mon. Wea. Rev., 126, 812-830, https://doi.org/10.1175/1520-0493(1998) $126<0812:$ TUOTLF $>2.0 . \mathrm{CO} ; 2$.

Pous, S., P. Lazure, and X. Carton, 2015: A model of the general circulation in the Persian Gulf and in the Strait of Hormuz: Intraseasonal to interannual variability. Cont. Shelf Res., 94, 55-70, https://doi.org/10.1016/j.csr.2014.12.008.

Reynolds, R. M., 1993: Physical oceanography of the Gulf, Strait of Hormuz, and the Gulf of Oman-Results from the Mt Mitchell expedition. Mar. Pollut. Bull., 27, 35-59, https://doi.org/ 10.1016/0025-326X(93)90007-7.

Saha, S., and Coauthors, 2011: NCEP Climate Forecast System Version 2 (CFSv2) selected hourly time-series products. National Center for Atmospheric Research, Computational and Information Systems Laboratory, accessed December 2017, https://doi.org/ 10.5065/D6N877VB.

Shchepetkin, A. F., and J. C. McWilliams, 2003: A method for computing horizontal pressure-gradient force in an oceanic model with a nonaligned vertical coordinate. J. Geophys. Res., 108, 3090, https://doi.org/10.1029/2001JC001047.

Simpson, J., C. Allen, and N. Morris, 1978: Fronts on the continental shelf. J. Geophys. Res., 83, 4607-4614, https://doi.org/ 10.1029/JC083iC09p04607.
Stern, M. E., 1968: T-S gradients on the micro-scale. Deep-Sea Res. Oceanogr. Abstr., 15, 245-250, https://doi.org/10.1016/00117471(68)90001-6.

Swift, S. A., and A. S. Bower, 2003: Formation and circulation of dense water in the Persian/Arabian Gulf. J. Geophys. Res., 108, 3004, https://doi.org/10.1029/2002JC001360.

Thoppil, P. G., and P. J. Hogan, 2009: On the mechanisms of episodic salinity outflow events in the Strait of Hormuz. J. Phys. Oceanogr., 39, 1340-1360, https://doi.org/10.1175/2008JPO3941.1.

— and - 2010a: A modeling study of circulation and eddies in the Persian Gulf. J. Phys. Oceanogr., 40, 2122-2134, https:// doi.org/10.1175/2010JPO4227.1.

— , and - 2010b: Persian Gulf response to a wintertime shamal wind event. Deep-Sea Res. I, 57, 946-955, https:// doi.org/10.1016/j.dsr.2010.03.002.

Valle-Levinson, A., 2010: Definition and classification of estuaries. Contemporary Issues in Estuarine Physics, Cambridge University Press, 1-11, https://doi.org/10.1017/CBO9780511676567.002.

—, and K. T. Bosley, 2003: Reversing circulation patterns in a tropical estuary. J. Geophys. Res., 108, 3331, https://doi.org/ 10.1029/2003JC001786.

Vic, C., G. Roullet, X. Capet, X. Carton, M. J. Molemaker, and J. Gula, 2015: Eddy-topography interactions and the fate of the Persian Gulf outflow. J. Geophys. Res. Oceans, 120, 67006717, https://doi.org/10.1002/2015JC011033.

Wang, T., W. R. Geyer, and P. MacCready, 2017: Total exchange flow, entrainment, and diffusive salt flux in estuaries. J. Phys. Oceanogr., 47, 1205-1220, https://doi.org/10.1175/JPO-D-16-0258.1.

Warner, J. C., W. R. Geyer, and J. A. Lerczak, 2005: Numerical modeling of an estuary: A comprehensive skill assessment. J. Geophys. Res., 110, C05001, https://doi.org/10.1029/2004JC002691.

, D. K. Ralston, and T. Kalra, 2020: Using tracer variance decay to quantify variability of salinity mixing in the Hudson River estuary. J. Geophys. Res. Oceans, 125, e2020JC016096, https://doi.org/10.1029/2020JC016096.

Warren, B. A., 2009: Note on the vertical velocity and diffusive salt flux induced by evaporation and precipitation. J. Phys. Oceanogr., 39, 2680-2682, https://doi.org/10.1175/2009JPO4069.1.

Wolanski, E., 1986: An evaporation-driven salinity maximum zone in Australian tropical estuaries. Estuarine Coastal Shelf Sci., 22, 415-424, https://doi.org/10.1016/0272-7714(86)90065-X.

Yao, F., and W. E. Johns, 2010a: A HYCOM modeling study of the Persian Gulf: 1. Model configurations and surface circulation. J. Geophys. Res., 115, C11017, https://doi.org/ 10.1029/2009JC005781.

- and - 2010b: A HYCOM modeling study of the Persian Gulf: 2. Formation and export of Persian Gulf water. J. Geophys. Res., 115, C11018, https://doi.org/10.1029/2009JC005788. 